\title{
Long noncoding RNAs: emerging players in thyroid cancer pathogenesis
}

\author{
Avaniyapuram Kannan Murugan', Arasambattu Kannan Munirajan² and Ali S Alzahrani1 \\ 1Division of Molecular Endocrinology, Department of Molecular Oncology, King Faisal Specialist Hospital and Research Center, Riyadh, Saudi Arabia \\ 2Department of Genetics, Dr ALM PG Institute of Basic Medical Sciences, University of Madras, Taramani, Chennai, India
}

Correspondence should be addressed to A K Murugan: akmurugan@gmail.com

\begin{abstract}
Thyroid cancer continues to be the most common malignancy of endocrine glands. The incidence of thyroid cancer has risen significantly over the past 4 decades and has emerged as a major health issue. In recent years, significant progress has been achieved in our understanding of the molecular mechanisms of thyroid carcinogenesis, resulting in significant diagnostic, prognostic and therapeutic implications; yet, it has not reached a satisfactory level. Identifying novel molecular therapeutic targets and molecules for diagnosis and prognosis is expected to advance the overall management of this common malignancy. Long noncoding RNAs (IncRNAs) are implicated in the regulation of various key cellular genes involved in cell differentiation, proliferation, cell cycle, apoptosis, migration and invasion mainly through modulation of gene expression. Recent studies have established that IncRNAs are deregulated in thyroid cancer. In this review, we discuss extensively the tumor-suppressive (for example, LINC00271, MEG3, NAMA, PTCSC1/2/3, etc.) and oncogenic (for example, ANRIL, FAL1, H19, PVT1, etc.) roles of various IncRNAs and their possible disease associations implicated in thyroid carcinogenesis. We briefly summarize the strategies and mechanisms of IncRNA-targeting agents. We also describe the potential role of IncRNAs as prospective novel therapeutic targets, and diagnostic and prognostic markers in thyroid cancer.
\end{abstract}

\author{
Key Words \\ - thyroid cancer \\ - papillary thyroid cancer \\ - IncRNAs \\ - oncogene \\ tumor suppressor \\ - diagnosis \\ - prognosis
}

\section{Introduction}

Thyroid cancer continues to be the most common endocrine malignant tumor. Over the past 40 years, the incidence of thyroid cancer has steadily escalated in many countries of the world (Fagin \& Wells 2016, Howlader et al. 2017, Siegel et al. 2017). Thyroid cancers generally originate either from follicular or parafollicular $\mathrm{C}$ cells. The majority of thyroid malignant tumors such as papillary thyroid cancer (PTC), follicular thyroid cancer (FTC), poorly differentiated thyroid cancer (PDTC) and anaplastic thyroid cancer (ATC) originate from follicular cell-derived thyroid cells. Differentiated thyroid cancer (DTC) comprises the common thyroid cancer types,
PTC and FTC. Medullary thyroid cancer is derived from chief cells or parafollicular $\mathrm{C}$ cells which account for a minor portion of thyroid cancer (DeLellis et al. 2004, Fagin \& Wells 2016). Among these subtypes (PTC, FTC, PDTC and ATC) of thyroid cancers, PTC is the major form of thyroid cancer accounting for approximately more than 85\% (Fagin \& Wells 2016). ATC is the most aggressive and deadly thyroid cancer accounting for less than $3 \%$ and its overall survival rate is only 3-5 months after initial diagnosis (Fagin \& Wells 2016, Howlader et al. 2017). Currently, the common treatment methods for DTC are total thyroidectomy followed in some patients 
with radioactive iodine remnant ablation and thyroid hormone-suppressive therapy (Cooper 2009, Fagin \& Wells 2016). In recent years, after the initial treatment, patients are closely followed by neck ultrasonography, serum thyroglobulin measurement and in some cases by whole body scanning of radioactive iodine and computed tomography, magnetic resonance imaging or positron emission tomography on a long-term basis in order to detect the recurrence at an early stage and implement therapeutic measures when necessary (Cooper 2009, Pacini \& Castagna 2012, Fagin \& Wells 2016). Although the outcome of DTC is excellent in the majority of cases, it partly shows a poor satisfactory outcome as tumor persistence, and the recurrence rate is $\sim 30 \%$ even after many years of remission (Cooper 2009, Pacini \& Castagna 2012, Grant 2015).

Though cancer is a multifactorial disease, it has been well ingrained that genetic, epigenetic alterations and environmental factors are the basis for carcinogenesis and these factors play pivotal roles in the pathogenesis and/or progression of the various types of human cancers including thyroid cancer (Vogelstein \& Kinzler 2004, Xing 2013, Fagin \& Wells 2016). For the past 30 years of study of molecular mechanisms, thyroid cancer facilitated understanding of various genetically deregulated genes of many pathways: among them, two key signaling pathways are at the heart of thyroid cancer pathogenesis. The mitogen-activated protein kinase (MAPK) and phosphatidylinositol-3-kinase (PI3K)/Akt pathways have been shown to be frequently altered by different mechanisms in thyroid cancer (Xing 2013, Fagin \& Wells 2016, Landa et al. 2016). PTC frequently harbors activating mutations in the genes such as RET/PTC, BRAF, RAS, etc., of the MAPK pathway (Grieco et al. 1990, Xing 2005, Hou et al. 2007, Agrawal et al. 2014, Murugan et al. 2016) except the ERK (Murugan et al. 2009) and infrequently harbors mutation in the genes such as EGFR, P53, EIF1AX, PPM1D, CHEK2, NF1, etc., (Masago et al. 2009, Murugan et al. 2011, Ricarte-Filho et al. 2012, Agrawal et al. 2014) but not commonly in the genes of PI3K/Akt pathway (Xing 2010, Murugan et al. 2015a). FTC and ATC commonly harbor genetic mutations/amplifications/fusions in genes such as P53, RAS, ALK, PIK3CA, PTEN, AKT, PDK1, RASAL1, RET, NTRK1/3, PAX8-PPAR $\gamma$, etc. (Hou et al. 2007, Liu et al. 2008, 2013a, Murugan \& Xing 2011, Landa et al. 2016). Recently, PDTC and ATC have been shown to harbor $B R A F$ mutations: $33 \%$ and $45 \%$, respectively (Landa et al. 2016). Thyroid cancers have been shown to be mutated in certain genes of the metabolic and regulatory pathways such as IDH1 (Hemerly et al. 2010, Murugan et al. 2010) and TERT (Landa et al. 2013, Liu et al. 2013b, 2014, Xing et al. 2014, Qasem et al. 2015), respectively. Genetic deregulation of these genes results in hyperactivation of MAPK and PI3K/Akt signaling pathways that drive the cell for uncontrolled cell proliferation, growth, survival, invasion and metastasis in thyroid cancer.

In thyroid cancer, genetic and epigenetic deregulations in the MAPK, PI3K/Akt and other signaling pathwayassociated genes altogether account for 90-95\% (Xing 2013, Agrawal et al. 2014, Fagin \& Wells 2016, Landa et al. 2016); the remaining $~ 5-10 \%$ of genetic and epigenetic factors involved in thyroid cancer are unidentified and their molecular basis is not well understood. Recently, long noncoding RNAs (lncRNAs) have been demonstrated to play crucial roles in thyroid tumorigenesis (Lan et al. 2015a, Yang et al. 2016, Wang et al. 2016, Liyanarachchi et al. 2016, Xu et al. 2016, Li et al. 2017a). IncRNAs and their potential role in follicular cell-derived thyroid tumorigenesis are the central focus of this review. To date, this is the first review to address lncRNA involvement in thyroid cancer pathogenesis. This review mainly focuses on the role of lncRNAs as being tumor-suppressive and oncogenic, and further discusses their potential importance as a therapeutic target, and diagnostic and prognostic biomarkers for the ever increasing deadly thyroid cancer.

\section{Noncoding ribonucleic acids (ncRNAs)}

In mammals, although $>90 \%$ of the genome is transcribed, only about $2 \%$ of the genome is subsequently translated. The remaining majority of the transcribed genes lack protein-coding capacity and are left un-translated. As these RNA transcripts do not encode for any proteins, they are grouped as ncRNAs. The noncoding genomic regions serve as a template for the transcription of a large number of ncRNAs in addition to their role as a substrate for DNA binding protein (Carninci et al. 2005). Based on the size of the ncRNAs, they are categorized into two groups including short ncRNAs and long ncRNAs. MicroRNAs (miRNAs), piwi-interacting RNAs (piRNAs), small interfering RNAs (siRNAs), transfer RNAs (tRNAs) and some ribosomal RNAs (rRNAs) are grouped under short ncRNAs. IncRNAs include long intergenic noncoding RNA (lincRNA), intronic long noncoding RNA (ilncRNA), natural sense or antisense transcript, promoter-associated long noncoding RNA (paRNA), promoter upstream transcript (PROMPT), repetitive element-associated noncoding RNA, pseudogene long noncoding RNA (plncRNA), transcribed ultraconserved region (T-UCR) and enhancer-like noncoding RNA (elncRNA). Among these 
ncRNAs, miRNAs are the most extensively studied ncRNAs in human cancers (Huarte 2015, Murugan et al. 2015b, Tye et al. 2015). Other types of ncRNAs have already been reviewed in thyroid cancer (Li \& Wang 2012, Kentwell et al. 2014, Zhang et al. 2016), while this review addresses only lncRNAs in thyroid cancer.

\section{IncRNAs and their biological functions}

lncRNAs, >200 nucleotides in length, do not code for proteins and they are shorter than mRNAs as lncRNAs have fewer exons. These RNA molecules vary in size with the length ranging from $200 \mathrm{bp}$ to $100 \mathrm{~kb}$. Recently, the ENCODE project revealed that $\sim 80 \%$ of the human genome is transcribed into 14,880 lncRNAs from 9277 loci (Derrien et al. 2012). The concept of lncRNAs was introduced more than 2 decades ago. However, the focus on lncRNAs has been neglected generally as the expression of lncRNAs are much lower than those of mRNAs (Carninci et al. 2005, Derrien et al. 2012), and exhibit evolutionarily poor sequence conservation across species (Taft et al. 2007). Currently, lncRNA research has moved to the forefront of human cancer research as recent findings revealed a crucial role of lncRNAs in gene modulation. IncRNAs are mainly involved in the epigenetic regulation of expression of various genes at different levels including chromatin, splicing, transcriptional and post-transcriptional. They epigenetically regulate expressions of many salient genes involved in vital cellular biological processes such as autophagy, cell differentiation, cell cycle regulation, cell proliferation, migration and invasion, apoptosis and mesenchymal stem cell differentiation (Fig. 1) (Huarte 2015, Tye et al. 2015).

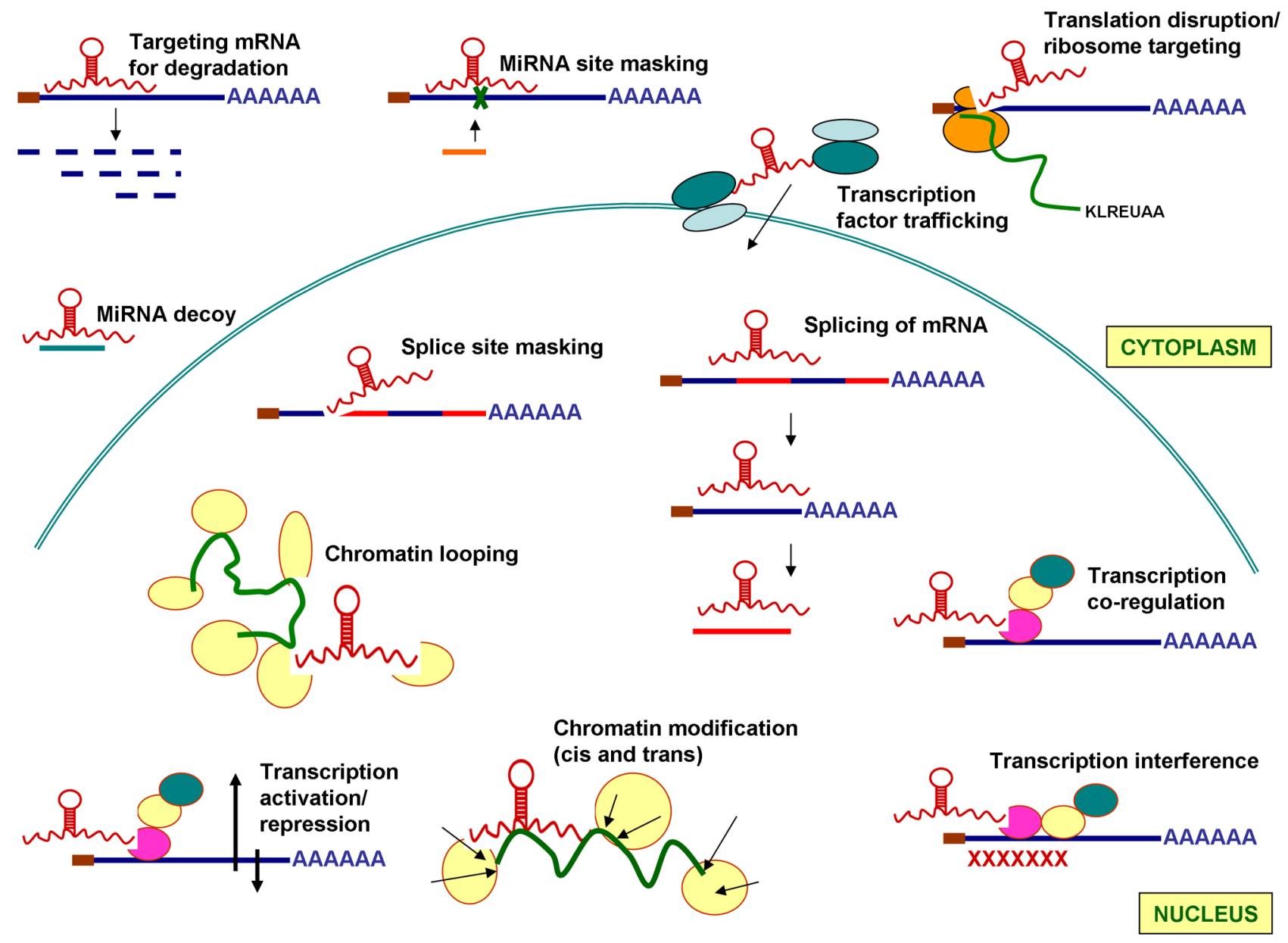

Figure 1

IncRNAs and their functions. This illustration shows various functions of IncRNAs. In the nucleus, IncRNAs are involved in chromatin looping, chromatin modification in both cis and trans, transcription regulation (activation or repression) and mRNA splicing. IncRNAs target mRNA for degradation or protection, transcription factor trafficking, miRNA site masking and translation disruption/ribosome targeting in the cytoplasm. A full colour version of this figure is available at https://doi.org/10.1530/ERC-17-0188. 


\section{IncRNAs in human cancers}

Concurrent knowledge on lncRNAs clearly shows that they are implicated in many types of human diseases, including cancer (Huarte 2015). Based on cellular function, lncRNAs could also be classified broadly into oncogenic and tumor-suppressive lncRNAs in a way similar to the protein-coding genes. For example, lncRNA HOTAIR has been known to be deregulated in a wide spectrum of human cancers such as oral, nasopharynx, breast, esophagus, lung, liver, pancreas, colon, endometrium and cervix cancers (Huarte 2015). Expression of PCA3 (prostate cancer antigen 3 ) is restricted to prostate tissue and it is highly overexpressed in tumors when compared to normal prostatic tissue of the same cases (Bussemakers et al. 1999). PCGEM1 is highly prostate-specific and its elevated expression has been associated with high-risk populations, such as African-Americans compared to Caucasian-Americans (Petrovics 2004). PRNCR1 (prostate cancer noncoding RNA 1) is upregulated in prostate cancer and has been reported to be highly associated with prostate cancer susceptibility in Europeans and AfricanAmericans (Chung et al. 2011). HULC (highly upregulated in liver cancer) has been found to be overexpressed both in hepatocellular carcinoma (Panzitt et al. 2007) and in gastric cancer and is also implicated in hepatic colorectal carcinoma metastasis (Matouk et al. 2009). Nonetheless, the variant rs7763881 in HULC has been found to be associated with a decreased risk of HCC in persistent carriers of HBV (Liu et al. 2012). Recently, CCAT1 has been demonstrated to be upregulated and shown to predict poor prognosis in oral squamous cell carcinomas (Arunkumar et al. 2017).

\section{IncRNAs in thyroid cancer}

\section{Genome-wide profile of IncRNAs in thyroid cancer}

lncRNAs play a crucial role in many key cellular functions and deregulations of IncRNAs have been identified in many complex human diseases including cancers. Recently, a genome-wide analysis (GWAS) of IncRNA expression profile in PTCs identified various up- and downregulated IncRNAs in PTC samples (Lan et al. 2015a). This group investigated the IncRNA and mRNA expression profiles in 62 PTC tissues with paired normal thyroid tissue by microarray and validated 10 differentially expressed lncRNAs using qRT-PCR. Gene functions were investigated using gene ontology and KEGG pathway analyses and two independent algorithms were used to predict possible target genes of these lncRNAs. In this microarray-based study, Lan and coworkers found thousands of significantly differentially expressed IncRNAs and mRNAs compared to nonthyroid cancer tissue (Lan et al. 2015a). Furthermore, 1805 deregulated IncRNAs have been found to have cis or trans target genes. In the cis target genes, 463 of them were found to be differentially expressed and it has been suggested that they might be regulated by lncRNAs in the process of PTC carcinogenesis. Among the top 20 upregulated IncRNAs, a minimum of 86 -fold to a maximum of 204-fold change has been observed. Furthermore, they observed a minimum of 47 -fold to a maximum of 148 fold changes among the top 20 downregulated lncRNAs. Of these IncRNAs, 10 lncRNAs have been identified as statistically significant and are differentially expressed as up/downregulated with the similar trend (Lan et al. 2015a). A human lncRNA-based microarray study found abnormal expression of 675 lncRNAs in 3 pairs of PTC compared with paired normal thyroid tissues (Yang et al. 2016). Moreover, analysis of 12 samples with matched normal tissue by RNA sequencing and qRT-PCR identified 188 differentially expressed lncRNAs. Among them, NONHSAT076747 and NONHSAT122730 were associated with lymph node metastasis (LNM), while the expression of NONHSAG051968 was correlated negatively with tumor size (Wang et al. 2016). However, except for a few, the majority of lncRNAs identified in these GWAS are largely uncharacterized. In order to understand the functional role of these deregulated lncRNAs in thyroid cancer, an individual functional characterization of these lncRNAs is warranted at least for the top 10-20 up/downregulated lncRNAs in PTCs.

Recently, the genome-wide RNA sequencing of 12 PTC tumors with adjacent normal tissue disclosed 218 differentially expressed lncRNAs in PTC. Among the deregulated IncRNAs, two (XLOC_051122 and XLOC_006074) were found to be significantly overexpressed in patients with wild-type BRAF and LNM (Liyanarachchi et al. 2016). Moreover, overexpression of these 2 lncRNAs was observed to correlate significantly with LNM and BRAF mutation status. If confirmed in further studies, these 2 lncRNAs could serve as a prognostic biomarker in PTC as they were associated with adverse prognostic risk factors.

In addition, $\mathrm{Xu}$ and coworkers performed array hybridization of 22 PTC tumor samples with matched normal tissues using SBC 4X180K human microarrays. Compared to the normal tissues, a total of 777 differentially expressed lncRNAs were identified in PTCs. Among them, 325 upregulated and 452 downregulated 
lncRNAs have been identified. Microarray expression data were further validated by the RT-PCR in 46 PTC tumor samples with paired normal tissues and they found consistency with the microarray data. It has also been shown that ENST00000537266 and ENST00000426615 were found to be upregulated in thyroid cancer (Xu et al. 2016). Recently, a microarray-based study detected 1593 differentially expressed lncRNAs in PTC (Li et al. 2017a). The later two study results are discussed in detail in this review under the subtitle: Oncogenic lncRNAs and their role in thyroid cancer.

\section{Tumor-suppressive IncRNAs and their role} in thyroid cancer

\section{NAMA (noncoding RNA associated with MAP kinase pathway and growth arrest)}

NAMA, the first lncRNA in thyroid cancer, was delineated by Albert de la Chapelle and his group a decade ago (Yoon et al. 2007). It showed several unique characteristic features distinguishing it from typical protein-coding counterpart genes. NAMA was assumed not to be a protein-coding gene but a noncoding RNA (ncRNA) as it lacked significant ORFs and most exons showed very low sequence conservation between human and mouse. The NAMA has been downregulated in PTCs with the BRAF (V600E) mutation that led the researchers to investigate whether NAMA could be modulated by the MAPK pathway. It has been demonstrated that NAMA was triggered upon treatment with BRAF or MEK inhibitors and it was also induced by serum depletion in NPA87 cells, but not in K1 cells with mutant BRAF that confers constitutive activation and helps the cells to continuously grow even in the absence of upstream signals. Moreover, NAMA has also been induced by inhibiting MEK in the HCT116 cell line suggesting that regulation of NAMA expression by the MAPK pathway was not exclusively specific to thyroid cells. These experimental observations suggested clearly that the NAMA could be a downstream target of MAPK pathway.

Treatment with the MEK inhibitor U0126 inhibited K1 and NPA87 cells at the G1 phase. Although $>90 \%$ of $\mathrm{K} 1$ cell arrest at the G1 phase resulted in clear induction of NAMA, under serum-free conditions, no significant shift of the K1 cell population into G1 or S was seen when compared with controls, while the NAMA expression was unchanged. On the other hand, under serum-free conditions, U0126-treated NPA87 cells showed >20\% increased cell cycle arrest at the G1 phase with NAMA induction. This association was further evidenced by sustained cell cycle arrest after DNA damage that accompanied NAMA upregulation, which suggests that NAMA is a direct target of the MAP kinase pathway, and hence NAMA induction results in cell growth arrest and apoptosis. Alternatively, it has been speculated that induction of NAMA could be secondary to cell cycle arrest and apoptosis. To rule this out, spliced forms of NAMA was overexpressed and unspliced NAMA was knocked down by siRNA. Nonetheless, it failed to detect any phenotypic changes, while NAMA was transfected and overexpressed in $\mathrm{K} 1$ cells. As only unspliced forms of NAMA are seen in thyroid cells, it has been hypothesized that the unspliced NAMA is likely to be the active form, perhaps in a tissue-specific manner (Yoon et al. 2007). Furthermore, siRNA-mediated knockdown of NAMA expression in $\mathrm{K} 1$ cells resulted in differential effects. Of two siRNAs, siN-210 induced apoptosis with a longerlasting effect while siN-630 induced cell cycle arrest with minimal strength. These observations suggested that the NAMA is likely to mediate a protective response. They also concluded that NAMA may also behave as a multifaceted molecule and/or has dual effects depending on the molecular interaction with various stimuli (Yoon et al. 2007).

A recent study investigated the role of NAMA in thyroid carcinogenesis by analyzing the expression of NAMA in a total of 40 pairs of PTC tissue and paired normal tissue by qRT-PCR. Expression of NAMA was significantly downregulated in PTC compared with normal tissue. Furthermore, as thyroid cell proliferation is mediated by the interaction of TSH and its receptor (TSHR), the effect of NAMA suppression on TSHR induction was evaluated using a PTC cell line (IHH-4). Nonetheless, silencing NAMA did not modulate TSHR level in IHH-4 cells suggesting that NAMA is likely to play a role in PTC not via TSHR (Zheng et al. 2016). These results suggest that NAMA is likely to function as tumor-suppressive lncRNA by playing a protective role in thyroid cancer. However, current knowledge on the understanding of the roles of NAMA in thyroid cancer is very limited. More work will be necessary, including the identification of the molecular targets of NAMA as the majority of lncRNAs are thought to play their key regulatory functions by interacting with DNA, RNA and proteins.

\section{PTCSC3 (papillary thyroid carcinoma susceptibility candidate $\mathbf{3}$ )}

GWAS addressed the genetic predisposition to PTC and found two independent SNPs (rs944289 and rs965513) in the chromosomal regions containing nonannotated genes 
and a significant association with PTC (Gudmundsson et al. 2009, 2012, Takahashi et al. 2010). At 3.2-kb downstream of the SNP rs944289 in 14q.13.3, Albert de la Chapelle and his group identified a lincRNA gene and named it PTCSC3. Its expression was evaluated in 46 PTC cases using qRT-PCR (Jendrzejewski et al. 2012). PTCSC3 expression was strongly downregulated in thyroid tumor tissue and the expression was associated with the risk allele (T) genotype (TT) $(n=21)$ compared with the genotype (CT) $(n=19)$. On the other hand, the genotype (TT) was associated with upregulation of PTCSC3 in normal thyroid tissue. The SNP rs944289 was identified in the binding site for C/EBP $\alpha$ and $\beta$. Risk allele has been shown to destroy the binding site in silico. Furthermore, in reporter assays, both C/EBP $\alpha$ and $\beta$ activated the PTCSC3 promoter and the risk allele $(\mathrm{T})$ reduced the activation compared with the nonrisk allele (C). Transient transfection of a PTCSC3expression plasmid in PTC cell lines which lack PTCSC3 expression (TPC-1 and BCPAP) resulted in decreased cell growth and downregulation of expression of genes involved in DNA replication, recombination, motility, morphology and apoptosis (Jendrzejewski et al. 2012). This study included only two cell lines and they usually accumulate genetic changes over time as a consequence; this was the major limitation of this study, although the results were distinct and conclusive. Furthermore, a future study is warranted with multiple cell lines and original tumor samples. Another study showed that the SNP rs 944289 was found to be associated with an increased risk of both benign and malignant thyroid tumors in Japanese patients (Rogounovitch et al. 2015). Although the expression of PTCSC3 is highly thyroid-tissue-specific, no somatic mutations or new SNPs were found in the PTCSC3 gene. The study suggested that the SNP rs944289 is likely to predispose to PTC via PTCSC3, a novel, tumorsuppressive lincRNA. Recently, five variants including the above-studied SNPs (rs944289 and rs965513) were assessed for the utility in the management of PTCs. It was found that larger tumor size and extrathyroidal expansion were associated with risk allele of the variant rs965513. Association with LNM and tumor multifocality was found with the rs2439302 suggesting an important function in clinical course, a role beyond predisposition to PTC (Jendrzejewski et al. 2016).

The same group investigated the possible molecular target of PTCSC3 as they have previously reported that the IncRNA located close to the variant rs944289 predisposes to PTC (Jendrzejewski et al. 2012) and alters expression of various cancer-associated key genes such as S100A4, RHOB, MOAP1, AKT, etc. (Jendrzejewski et al. 2015). The PTC cell lines (BCPAP and TPC-1) were stably transfected with a mammalian expression vector containing the PTCSC 3 or empty vector. Analysis of clones of both TPC-1 and BCPAP cell lines which stably express PTCSC 3 by qPCR found that the transcript of S100A4 is the most significantly downregulated gene under stable expression of PTCSC3. Furthermore, analysis of S100A4 and PTCSC3 expression in 74 PTC tumor tissues with paired normal thyroid tissues revealed that S100A4 was significantly upregulated, while PTCSC3 was downregulated in tumor tissues compared to normal tissues. The expression level of S100A4 has been associated moderately with PTCSC3 expression in normal thyroid tissue. Stable overexpression of PTCSC3 suppressed the migration and invasion potential of BCPAP cells through transcriptionally downregulating the VEGF and MMP-9. Moreover, PTCSC3 stable overexpression also downregulated the expression of S100A4 in BCPAP cells (Jendrzejewski et al. 2015). Furthermore, PTCSC3 was shown to counteract miR-574-5p and inhibit significant cell growth, arrest cell cycle and enhance apoptosis in thyroid cancer cells (Fan et al. 2013). In support of this idea, recently, PTCSC3 was identified to be significantly downregulated in PTCs (Zheng et al. 2016). These experiments clearly demonstrated that PTCSC3 has tumor-suppressive properties and downregulates $S 100 A 4$, which results in inhibition of PTC cell migration and invasion.

\section{PTCSC2 (papillary thyroid cancer susceptibility candidate 2)}

Another SNP identified by GWAS was rs965513 and the risk allele (A) of this SNP has been demonstrated to predispose strongly to PTC. It was localized at $9 \mathrm{q} 22$ (a 60-kb length from the FOXE1 gene). Albert de la Chapelle and his group found yet another novel lincRNA gene and named it PTCSC2 (He et al. 2015). Spliced PTCSC2 isoform is expressed specifically in normal thyroid, while the PTCSC2 unspliced form is invariably highly expressed in thyroid, in both adult and fetal brain. Expression analysis of unspliced PTCSC2 and 4 spliced isoforms in 6 thyroid cancer cell lines showed that the expression of PTCSC2 was undetectable in BCPAP, C646 and FTC133, and found to be significantly downregulated in KTC1, SW1736 and TPC1 cells compared with normal thyroid tissue. On the other hand, expression analysis in 65 PTC cases showed a low expression of both unspliced and spliced isoforms compared with matched normal tissue. Nevertheless, they found no significant association of rs965513 with expression levels of PTCSC2 in both unspliced and spliced 
transcripts from PTC tumors. Besides, in normal thyroid tissue, a low expression of unspliced PTCSC2, FOXE1 and TSHR has been strongly correlated with the risk allele (AA) of rs965513. The PTCSC2 unspliced form has also been correlated significantly with age and CLT. To understand the cellular role of PTCSC2, BCPAP cells were transiently transfected with a PTCSC2-c expression construct that strongly modulated the expression of cell cycle and cancerassociated genes (coding and noncoding) (He et al. 2015). Recently, the same group experimentally demonstrated that myosin-9 could bind to PTCSC2 and regulate FOXE1: this could be the mechanism underlying predisposition to PTC, induced by rs965513 (Wang et al. 2017). These data suggest that the lincRNA gene PTCSC2 is likely to function as a tumor-suppressor gene and genetically predisposes to PTC.

\section{MEG3 (maternally expressed 3 )}

lncRNA-MEG3 was significantly downregulated in PTC tissues with LNM compared to that of primary thyroid cancer. Furthermore, it has been found that the low expression level of MEG3 was strongly correlated with LNM (Wang et al. 2015). Moreover, forced expression of MEG3 in TPC-1 and HTH83 thyroid cancer cell lines could significantly decrease cell migration and invasion. Besides, dual luciferase assay results revealed that Rac1 was downregulated by MEG3 at the post-transcriptional level, through targeting 3'UTR. In PTC tissues, MEG3 expression level has been found to be negatively correlated with expression of Rac1 (Wang et al. 2015). These results collectively suggest that MEG3 could act as a novel tumor suppressor involved in the regulation of thyroid cancer cell migration and invasion by molecular targeting of Rac1.

\section{NONHSAT037832}

NONHSAT037832, a novel IncRNA, has recently been investigated for its expression in some cell lines and 87 PTCs with matched adjacent normal thyroid tissues by qRT-PCR. NONHSAT037832 has been found to be downregulated in PTC tissues compared with normal tissues (median fold change 4.2). It has also been found to be significantly decreased in two PTC cell lines K1 and IHH4 compared with Nthy-ori 3-1 (a normal thyroid cell line) but there was no difference between BCPAP and normal cells. Moreover, NONHSAT037832 downregulation was significantly associated with LNM and tumor size but not with other clinical features (Lan et al. 2015b). These results suggest that NONHSAT037832 is likely to be a tumor-suppressive lncRNA. Although NONHSAT037832 has been suggested to play a role in tumorigenesis via regulation of PGF expression, the mechanism is not clearly known and warrants further investigation.

\section{LINC00663 (long intergenic noncoding RNA 663)}

LINC00663 is normally well expressed in tissues of the thyroid and uterus but not in skeletal muscle tissues (Bozgeyik et al. 2016). Expression analysis of human cancer cell lines and normal tissues using qRT-PCR demonstrated that LINC00663 is differentially expressed in cancer cell lines. LINC00663 expression has been discovered to be highly decreased in the BCPAP thyroid cancer cell line. Further analyses exhibited the presence of a novel exonic region between exons 2 and 3 and that led to the identification of five potential splice variants showing a high level of variation among them. This group also studied the secondary structures of these variants with minimum free energy and demonstrated that they have potential putative miRNA binding sites in these variants (Bozgeyik et al. 2016). Nevertheless, the role of LINC00663 in human carcinogenesis is yet not well understood; further works are essential and indispensable to find the role of LINC00663 in human cancers including thyroid cancer. Moreover, judging from the expression analysis, LINC00663 is likely to act as a tumor suppressor rather than an oncogene as this lncRNA is demonstrated to be downregulated in the majority of human cancer cell lines (DU-145, PC3, HGC-27, CRL-1469, A549 and MCF7) including BCPAP, a thyroid cancer cell line.

\section{LINC00271}

Annotation of 2773 lncRNAs from the TCGA dataset found 220 differentially expressed lncRNAs, of which CTBP1-AS2, HAR1A, HAS2-AS1, FAM41C and LINC00271 have been observed to be closely associated with recurrence. In multivariate-mediated analyses, LINC00271 has been found to be an independent risk factor for ETE, LNM and tumor stage III/IV and recurrence after adjusting the BRAFV600E clinicopathological factors. In addition, expression analysis of 50 PTC patients with paired normal tissues revealed that LINC00271 has been downregulated significantly in PTCs. Moreover, gene set enrichment analysis (GSEA) predicted that genes involved in the p53 and JAK/STAT signaling pathways, and genes implicated in cell adhesion and cell cycle were remarkably enriched in PTCs with a lower expression of LINC00271 (Ma et al. 2016). This study concluded that LINC00271 is likely to play the role of a tumor-suppressor gene and it could also serve as a potential predictor of poor prognosis in PTC 


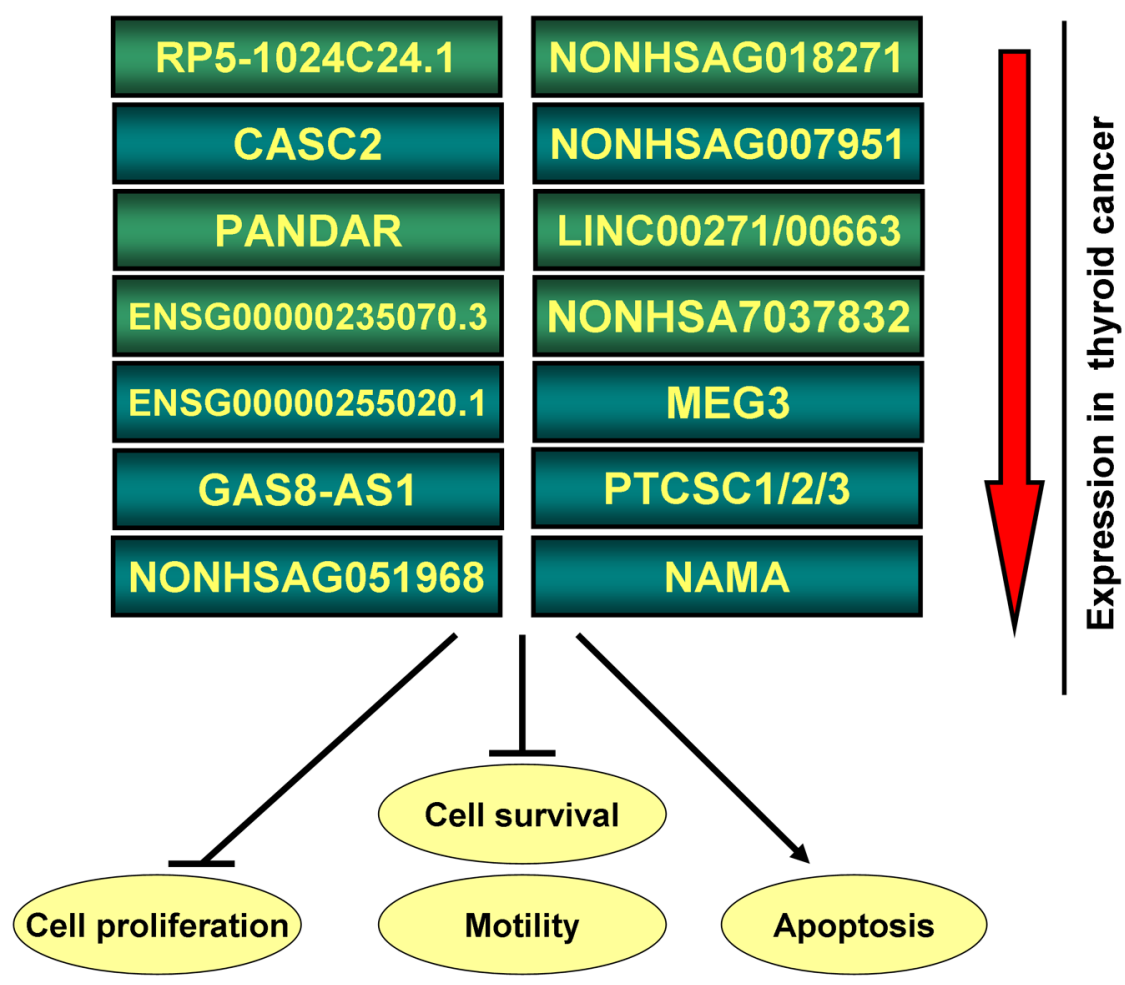

\section{Figure 2}

Tumor-suppressive effects of various IncRNAs in thyroid cancer. Thyroid cancer-specific IncRNAs shown above regulate expression by repressing/ tightly controlling transcription of various genes involved in proliferation, cell cycle regulation, cell motility, etc. In thyroid cancer, context-dependent downregulation of these IncRNAs results in transcriptional activation of various genes of key cellular signaling pathways. A full colour version of this figure is available at https://doi. org/10.1530/ERC-17-0188. patients. The lncRNAs discussed above and listed in Table 1 are more likely to function as a tumor suppressor in thyroid cancer (Fig. 2 and Table 1).

\section{Oncogenic IncRNAs and their role in thyroid cancer}

\section{BANCR (BRAF-activated long noncoding RNA)}

BANCR has been implicated in cell proliferation and autophagy in PTC (Wang etal. 2014a). A qRT-PCR-mediated study on a total of 40 pairs of PTC and its paired normal tissues identified that BANCR expression was significantly upregulated in PTCs compared to adjacent normal tissue. Thyroid cell proliferation and its subsequent function are implicated by the interaction of TSHR. Transient transfection of siRNAs specifically targeting BANCR showed significant downregulation of TSHR in IHH-4 cells (Zheng et al. 2016). Furthermore, siRNA-BANCRtransfected cells showed much slower proliferation than the cells transfected with the scrambled siRNA control. Consistent with the proliferation assay, fewer colonies were formed in cells lacking BANCR compared to the control siRNA-transfected IHH-4 cells in the colony formation assay. Interestingly, expressions of cyclin D1 both at the mRNA and the protein level were observed to be significantly decreased in siRNA-BANCR-transfected cells compared to the control-siRNA-transfected IHH-4 cells. In contrast, mRNAs of cyclin A1, E1 and B1 were unaltered after silencing BANCR, although cyclin A1 and E1 proteins were slightly but not significantly decreased in BANCR-silenced cells. BANCR was found to be highly enriched in the EZH2 group compared to the IgG control group and expression of TSHR was significantly lower in BANCR-knockdown cells compared to the control cells suggesting that BANCR may enhance TSHR expression through binding to EZH2 (Zheng et al. 2016). Taken together, this series of experimental results suggest that BANCR is a typical oncogenic lncRNA and an important molecule for a therapeutic target in PTC (Fig. 3). In contrast, a recent study demonstrated that BANCR functions as a tumor suppressor in PTC (Liao et al. 2017). Although it has been speculated that BANCR could function as both an oncogene and a tumor-suppressor gene (Liao et al. 2017), it is not very clear whether it could be bifunctional in PTC itself and warrants further studies to clarify these findings.

\section{PVT1 (plasmacytoma variant translocation 1)}

An extensive expression analysis of PVT1 in 84 thyroid cancer tissues showed that the relative mRNA expression was significantly upregulated in cancer cells compared to adjacent normal cells. Consistent with these results, the PVT1 expression was identified to be significantly higher in various thyroid cancer cell lines such as IHH-4 (PTC), FTC-133 (FTC) and 8505c (ATC) compared to the normal http://erc.endocrinology-journals.org https://doi.org/10.1530/ERC-17-0188 (c) 2018 Society for Endocrinology Published by Bioscientifica Ltd. Printed in Great Britain 

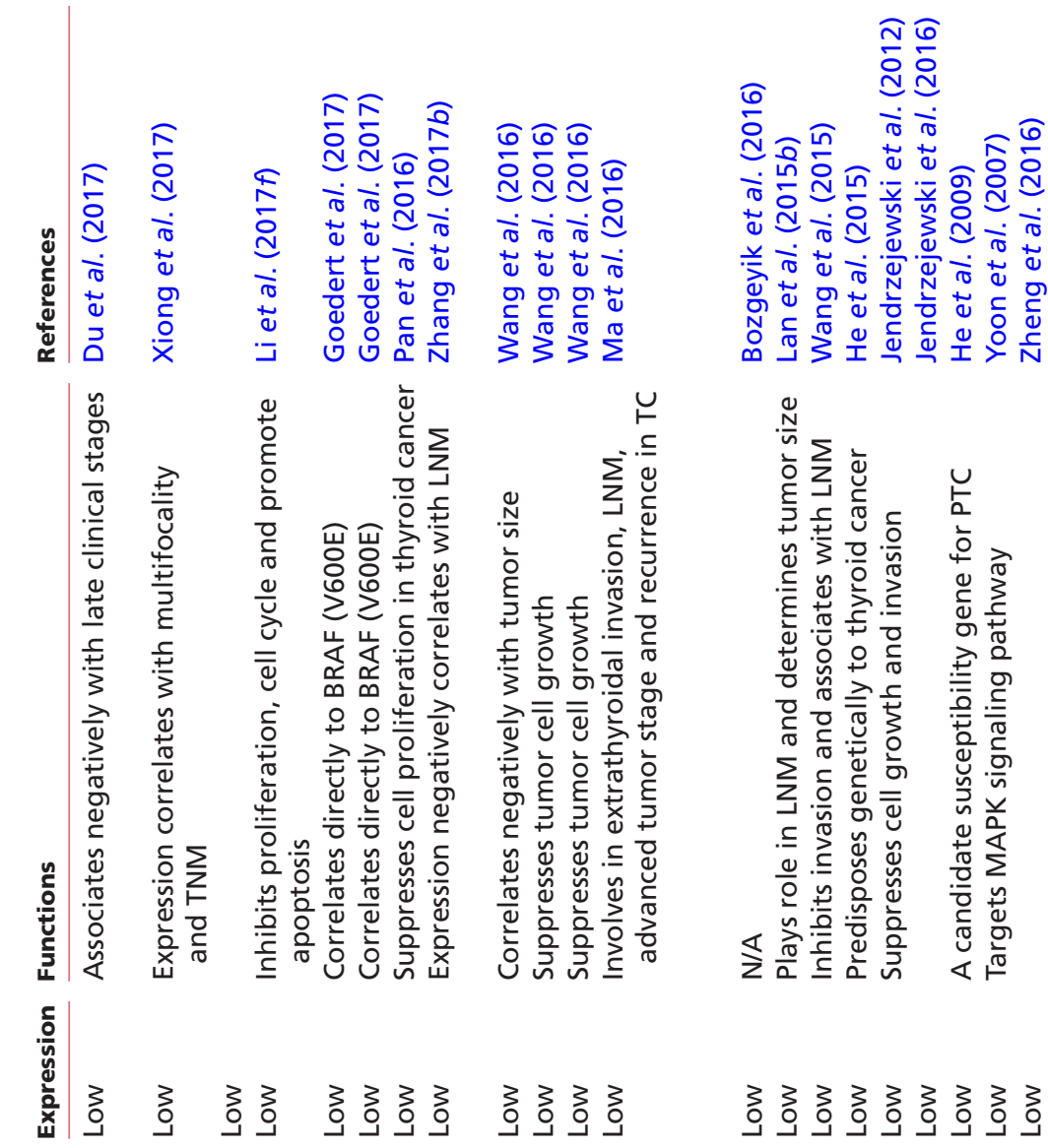

莺

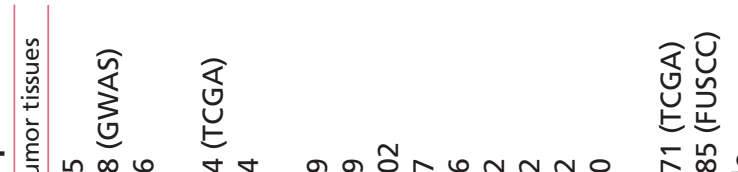

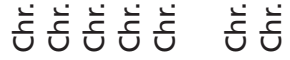

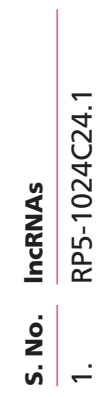

กํ.

苍造

ชิ 


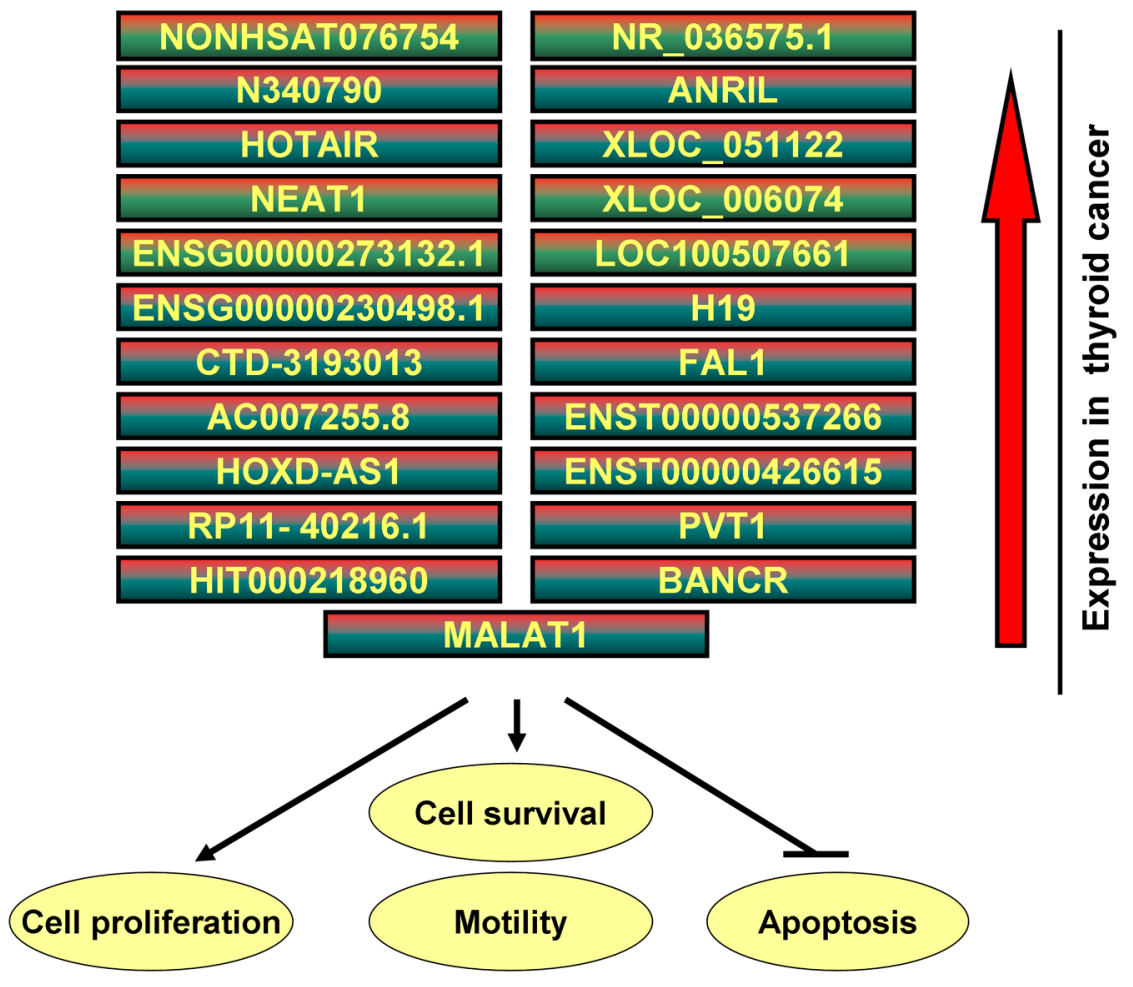

Figure 3
Various oncogenic IncRNAs implicated in thyroid
cancer. Deregulation of various IncRNAs is
implicated in thyroid cancer. IncRNAs regulate
expression by controlling transcription of various
genes involved in the key cellular processes such
as proliferation, cell cycle, survival, apoptosis, cell
motility, etc. In thyroid cancer, context-dependent
upregulation of these IncRNAs results in
transcriptional activation of various genes of
important cell signaling pathways that result in
deregulated cellular processes paving the way to
carcinogenesis. A full colour version of this figure
is available at https://doi.org/10.1530/ERC-17-0188. counterpart Nithy-ori 3-1 cell line (Zhou et al. 2015). Moreover, siRNA-mediated inhibition of PVT1 in IHH-4 cells (transfected with an siRNA-PVT1 vector) showed significantly slower growth of IHH-4 cells from 48 to $96 \mathrm{~h}$ when compared to vector-alone-transfected cells. On the other hand, FTC-133 and 8505C cells transfected with siRNA-PVT1 showed slower growth from 72 to $96 \mathrm{~h}$. Similar to these proliferation assay results, the number of colonies formed by all three cell lines in the colony formation assay was significantly decreased in cells lacking PVT1. Furthermore, flow cytometry-mediated exploration of cellular DNA content, cell cycle profiling and cell proliferation revealed that the percentage of cells at the G1 stage was significantly enhanced when the PVT1 was silenced in all three of the thyroid cancer cell lines (IHH-4, FTC-133 and 8505C) as compared with control cell lines which suggests that suppression of PVT1 could result in cell cycle arrest at G1. This was clearly reflected in the expression of various proteins involved in cell cycle kinetics, as cyclin D1 was significantly decreased when cells were transfected with siRNA-PVT1 compared with controls cells. On the contrary, it has been shown that mRNA expressions of cyclin A1, B1 and E1 were not significantly changed, albeit proteins of A1, B1 and E1 were slightly but not significantly reduced in PVT1-silenced cells. In addition, it has been shown that
siRNA-mediated PVT1 suppression resulted in a decreased expression of TSHR (mRNA and protein) in IHH-4 cells. A similar tendency has also been observed in two other thyroid cancer cell lines (FTC-133 and 8505C) suggesting a positive correlation of PVT1 expression with TSHR (Zhou et al. 2015). As observed with BANCR (Zheng et al. 2016), PVT1 was also accumulated by EZH2 compared to that in control cells in all three thyroid cancer cell lines (IHH-4, FTC-133 and 8505C) implying that lncRNA is likely to bind to EZH2. Further experiments confirmed that silencing PVT1 could significantly decrease TSHR expression by targeting its promoter in three different cell lines. These results collectively suggest that PVT1 suppression decreases TSHR expression via binding to EZH2 in thyroid cancer cell lines (Fig. 4). Apart from thyroid cancer, PVT1 has also been implicated in the tumorigenesis of various human cancers (Takahashi et al. 2014, Wang et al. 2014b). It has been shown that PVT1 overexpression is correlated with colon cancer prognosis via the regulation of cell apoptosis (Takahashi et al. 2014) and overexpression of IncRNA has been shown to be involved in promoting stem cell proliferation in hepatocellular carcinoma (Wang et al. 2014b). Moreover, the results of these studies suggest that PVT1 is likely to function as an oncogene in various types of human cancers including thyroid cancer.
C) 2018 Society for Endocrinology Published by Bioscientifica Ltd. Printed in Great Britain 

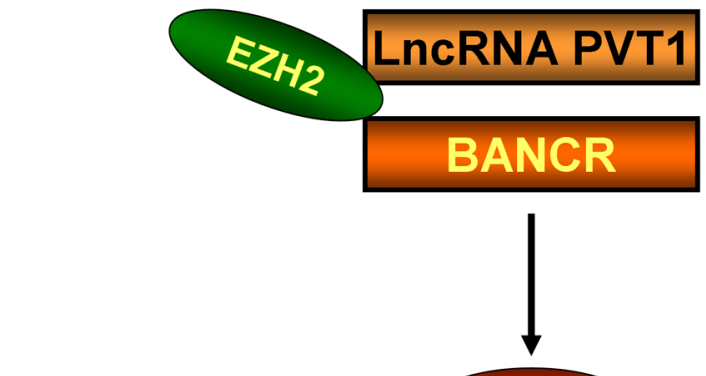

TSHR

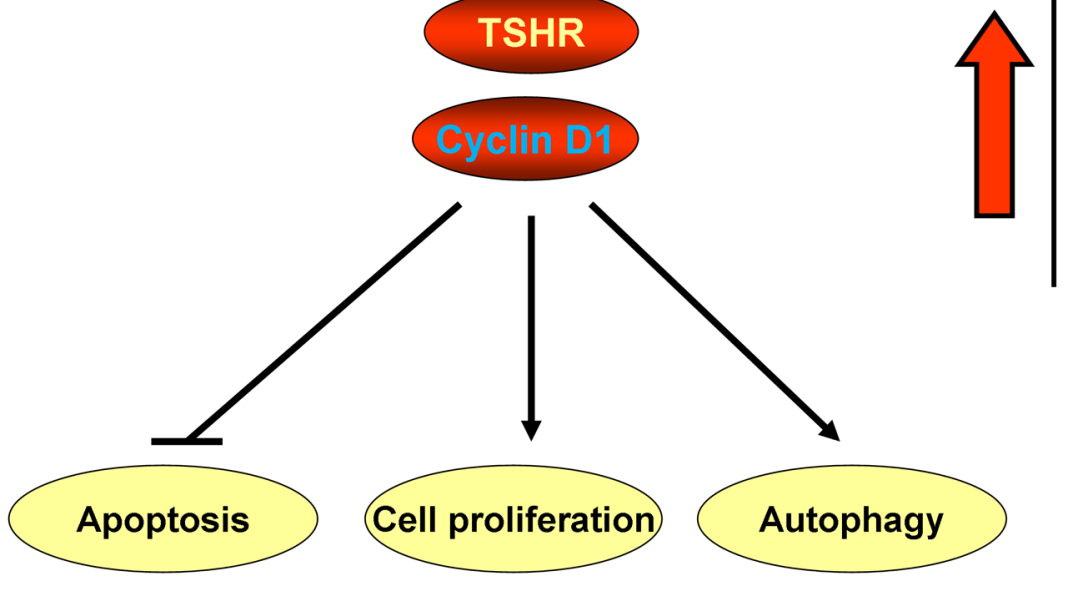

Figure 4

Oncogenic effect of PVT1 and BANCR IncRNAs in thyroid cancer. IncRNAs PVT1 and BANCR activate the transcription of various genes implicated in regular cell growth signaling pathways of normal thyroid cells. Deregulation of IncRNA machinery results and upregulation of IncRNAs PVT1 and BANCR that hyperactivate the transcription of various key cellular growth controlling genes in thyroid cancer. A full colour version of this figure is available at https://doi.org/10.1530/ERC-17-0188.

\section{ENST00000537266 and ENST00000426615}

As a result of array hybridization, 10 candidate lncRNAs were identified including ENST00000537266 and ENST00000426615. They were found to be expressed more than tenfold differentially in PTC tissues compared to normal tissues (Xu et al. 2016). A subsequent RT-PCR analysis found that ENS-266 and ENS-615 were found to be consistently upregulated compared with adjacent normal tissues in 46 cases. Transfection of siRNAs against ENS-266 and ENS-615 in TPC-1 cells revealed that cell proliferation was significantly reduced in Si-266/Si-615-transfected TPC- 1 cells at various time points $(24,36,48$ and $72 \mathrm{~h})$. In Edu assay, Hoechst-stained nuclei in all three (Si-NC, Si-266 and Si-615) transfected TPC-1 cells were dense and contracted. Despite the percentage of Edu-positive cells, the number of colonies was significantly decreased in Si-266/Si-615-transfected TPC-1 cells compared with Si-NC cells.

Interestingly, a further functional analysis showed no significant difference in cell apoptosis between Si-266/ Si-615-transfected groups and the control group in TPC-1 cells. However, in cell cycle analysis, the cell proportion was significantly enhanced in the G1 phase but lowered in S and G2 phases in TPC-1 cells transfected with Si-266. On the other hand, they also observed an enhanced amount of cells at the G1 phase and also showed a reduction in the $S$ phase and no change in the G2 phase in TPC-1 cells transfected with Si-615. A significant decrease in cell migration was observed in both trans-well and scratch assay in Si-615-transfected TPC-1 cells, while there was no significant change observed in Si-266-transfected TPC-1 cells suggesting that ENS-615 has a major role in cell motility but not ENS-266. Moreover, structural prediction of both ENS-266 and ENS-615 revealed that these lncRNAs are likely to interact with BRAF, FOXE1, SIN1, TERT, NRG1, GL1 and MBIP (Xu et al. 2016). These results strongly suggest that both lncRNAs are likely to play an oncogenic role in thyroid carcinogenesis.

\section{FAL1 (focally amplified long noncoding on chromosome 1)}

An extensive expression level analysis of FAL1 and $p 21$ in 100 PTC samples and matched normal thyroid tissues revealed that the expression of FAL1 was significantly upregulated in PTCs than in normal tissues (Jeong et al. 2016). Unlike in other human cancers, $p 21$ expression was increased when compared to the matched normal tissues, suggesting that $\mathrm{p} 21$ is not negatively modulated by FAL1 in PTC cells and this result was consistent with Western blot analysis of protein samples. In addition, PTC cell lines also showed increased p21 levels. Furthermore, immunohistochemical staining data from the Human Protein Atlas revealed that p21 was 
easily detectable only in PTC tissues, not in follicular neoplasms, suggesting that p21 is active in PTC tumor tissues. A comparison of 30 PTC patients with the highest FAL1 expression against 30 cases with the lowest FAL1 expression showed that patients with high FAL1 expression could increase the risk of multifocality, suggesting that FAL1 expression is likely to affect tumor behavior and generate aggressive features of PTC. Furthermore, GSEA from open-source microarray data revealed a unique gene set for the cell cycle, including E2F1/2, VEGFA and cyclin D1, which was accumulated in the FAL1-upregulated samples, and this result has also been consistently reflected upon FAL1 overexpression in TPC1 and BCPAP cell lines (Jeong et al. 2016).

\section{H19 (imprinted maternally expressed transcript)}

lncRNA H19 was shown to be overexpressed and implicated as an oncogene in many human cancers (Liu et al. 2016). Recently, H19 has been demonstrated to be highly expressed in thyroid cancer cell lines and tumor samples when compared with normal thyroid cell lines and tissues (Liu et al. 2016). Furthermore, overexpression of H19 in TPC-1 and NIM thyroid cancer cell lines showed increased proliferation, migration and invasion. On the other hand, knockdown of H19 in the same cell lines decreased the cell viability, migration and invasion, and triggered growth arrest both in vitro and in vivo. This oncogenic lncRNA has been identified as a target of miR-17-5p. Moreover, $\mathrm{H} 19$ has been shown to antagonize miR-17-5p upon overexpression of its target YES1 and suppressed miR-17-5p-induced cell cycle progression (Liu et al. 2016). These results suggest that the oncogenic H19 is likely to also function as a competitive endogenous RNA.

\section{LOC100507661}

A recent study analyzed 2394 tumor SNP arrays from 12 types of cancer (Hu et al. 2014). Upon verification of 56 potential cancer-promoting genes from the aforementioned study, Kim et al. (2016) finally selected 3 candidate lncRNAs for further functional study. Among those 3 lncRNAs, LOC100507661 has been shown to be strongly overexpressed in thyroid cancer tissues compared to paired normal tissue. LOC100507661 has been demonstrated to be highly expressed and easily detectable in PTC (TPC1 and BCPAP) and ATC (C643 and 8505C) cell lines but not in FTC (FTC133) cell lines. Furthermore, stable overexpression of LOC100507661 resulted in enhanced cell proliferation, migration and invasion of thyroid cancer cells. In addition, it has been found that LOC100507661 expression was always high (60/64) and the high expression was more frequently associated with LNM in PTC samples (Kim et al. 2016). These results suggest that LOC100507661 is likely to function as an oncogenic lncRNA and could be a predictive prognostic biomarker in thyroid cancer.

\section{XLOC_ 051122 and XLOC_006074}

A genome-wide expression screening of 12 PTC tumors with paired normal tissue identified 218 differentially expressed lncRNAs (Liyanarachchi et al. 2016). Among them, a significant overexpression of 2 lncRNAs (XLOC_051122 and XLOC_006074) was found, particularly in PTC patients with no BRAF mutation. It has also been shown that higher levels of these 2 lncRNAs were detected in PTC cases with LNM suggesting oncogenic and strong prognostic roles of these novel lncRNAs in PTC. Though a distinct prognostic role of novel lncRNAs has been identified, the molecular mechanisms and their role in thyroid cancer are largely unknown and future works are warranted to supplement these findings.

\section{HIT000218960}

IncRNA microarray analysis of 6 pairs of PTCs with their paired normal tissue and further validation in 55 pairs of PTCs detected that HIT000218960 was significantly overexpressed in PTC. It was significantly correlated with TNM stage, LNM and multifocality and was also associated positively with the HMGA2 (high-mobility group AT-hook 2) oncogene. Moreover, downregulation of HMGA2 was observed in HIT000218960-knockdown PTC cell lines (TPC1 and BCPAP) and further functional analysis showed decreased cell growth, migration and invasion in vitro (Li et al. 2017a). These results suggest that HIT000218960 is likely to function as an oncogenic lncRNA by modulating HMGA2 expression.

\section{ANRIL (antisense noncoding RNA in the INK4 locus)}

This study detected expressions of ANRIL by qRT-PCR in 105 thyroid cancer patients compared with adjacent normal tissues. It has been shown that ANRIL was highly expressed in thyroid cancer, and siRNA-mediated ANRIL silencing in TPC-1 and SW579 cells inhibited proliferation, invasion and metastasis via the TGF- $\beta /$ Smad pathway (Zhao et al. 2016). These results collectively suggest that ANRIL is a typical oncogene. http://erc.endocrinology-journals.org https://doi.org/10.1530/ERC-17-0188
(C) 2018 Society for Endocrinology Published by Bioscientifica Ltd. Printed in Great Britain 


\section{NR_036575.1}

Expressions of this novel lncRNA were evaluated in 83 paired thyroid cancer and normal tissues and the results revealed that NR_036575.1 was significantly upregulated in thyroid cancer tissues. Furthermore, the expression of NR_036575.1 was associated with tumor size and extrathyroidal invasion. Establishment of two receiver-operating characteristic (ROC) curves predicted that NR_036575.1 could be a potential biomarker for identifying PTC (Sun et al. 2016). Moreover, NR_036575.1 knockdown experiments showed significant inhibition of TPC-1 cells suggesting that NR_036575.1 is likely to act as an oncogene in thyroid cancer.

\section{MALAT1 (metastasis-associated lung adenocarcinoma transcript 1)}

Higher level expressions of MALAT1 and IQGAP1 were detected in a thyroid cancer cell line and tissues compared with normal control. A series of experiments in this study demonstrated that MALAT1 could upregulate the expression of IQGAP1. MALAT1 knockdown resulted in decreased proliferation and invasion of FTC-133 cells. In turn, IQGAP1 knockdown reversed MALAT1overexpression-induced increased cell proliferation and invasion of thyroid cancer cells. MALAT1-induced tumor growth has been verified in nude mice (Huang et al. 2016). These results suggest that MALAT1 functions as an oncogene via regulation of IQGAP1 expression. Recently, expression analysis of MALAT1 on 195 benign and thyroid cancer cases by tissue microarrays for RNA in situ hybridization and RT-PCR revealed that MALAT1 is well expressed in both normal and tumor tissues of a thyroid. However, it has been found that MALAT1 is upregulated during the progression of normal tissue to cancer tissue. In contrast, compared to normal tissue, MALAT1 was shown to be significantly downregulated in PDTCs and ATCs. Furthermore, TGF- $\beta$-mediated induction of epithelial to mesenchymal transition (EMT) in TPC-1 cells resulted in upregulation of MALAT1 expression, suggesting a potential role of MALAT1 in EMT-mediated thyroid cancer progression (Zhang et al. 2017a).

\section{HOTAIR (HOX transcript antisense RNA)}

Although HOTAIR has been known to be widely deregulated in human cancers, its role is largely unclear as only a few studies were conducted in thyroid cancer. Initially, a study investigated the involvement of 3 haplotype-tagging SNPs of HOTAIR in PTC and found that HOTAIR SNP (rs920778) was a PTC-susceptibility variant and further demonstrated that HOTAIR acts as an oncogene (Zhu et al. 2016). A study based on TCGA and Gene Expression Omnibus data analysis showed that HOTAIR has been significantly overexpressed, associated with poor survival of thyroid cancer patients and likely to play a role in thyroid carcinogenesis via the Wnt signaling pathway (Li et al. 2017b). These results suggest that HOTAIR is an onco-lncRNA and its overexpression could serve as a biomarker associated with poor outcome in thyroid cancer.

\section{NONHSAT076754}

Expression analysis of NONHSAT076754 in 72 PTC samples (37 metastatic and 35 nonmetastatic) detected upregulation of NONHSAT076754 in 37 metastatic compared with nonmetastatic PTC cases and overexpression has been associated with LNM in PTC. Although NONHSAT076754 has been detected originally as an upregulated IncRNA, the experimental results of an overexpression study did not support its role in cell proliferation. Nevertheless, it strongly promoted migration and invasion of TPC1 cells and this activity was significantly reversed upon NONHSAT076754 knockdown in $\mathrm{K} 1$ cells, suggesting that it could serve as a potential auxiliary biomarker which may aid ultrasonography in predicting cervical LNM of PTCs (Xia et al. 2017).

\section{NEAT1 (nuclear-enriched abundant transcript 1)}

NEAT1 has been identified to be overexpressed, while miRNA-214 had been downregulated in thyroid cancer patients. Knockdown of NEAT1 resulted in decreased cell survival and motility with $\beta$-catenin (a direct target of miRNA-214) downregulation. Moreover, in thyroid cancer cells, upregulation of NEAT1 strongly promoted tumor progression and tumor size increase in vitro and in vivo, respectively. On the other hand, these cells showed a lower expression of miRNA-214 (Li et al. 2017c). These results suggest that overexpression of NEAT1 could result in the onset of thyroid cancer and that NEAT1 may act as an oncogenic lncRNA as it drives progression of thyroid cancer via modulation of miRNA-214 expression. The lncRNAs studied above and other lncRNAs listed in Table 2 are more likely to function as oncogenes in thyroid cancer (Fig. 3 and Table 2).

\section{Role of IncRNAs as therapeutic targets, and diagnostic and prognostic biomarkers}

lncRNAs have been found to be differentially expressed in human cancer and their overexpression or knockdown 


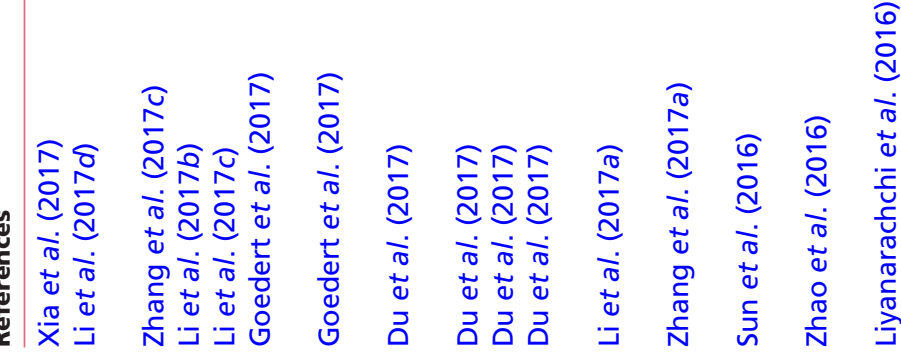

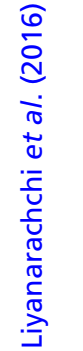

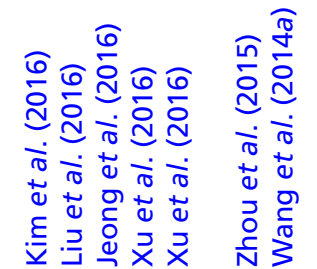

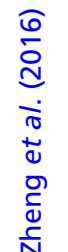

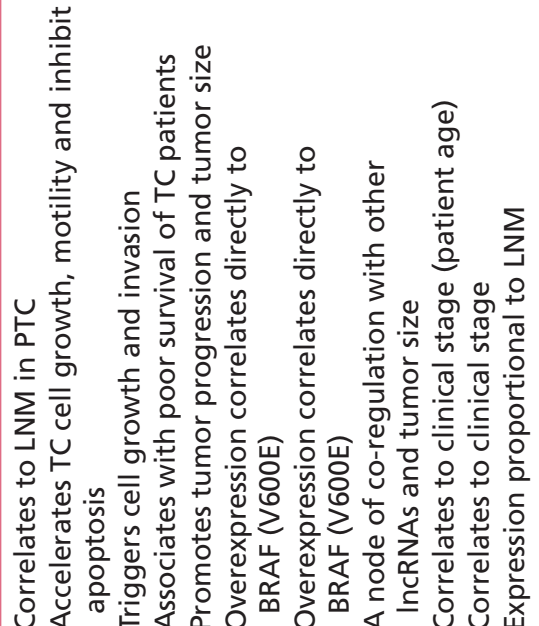

든 을

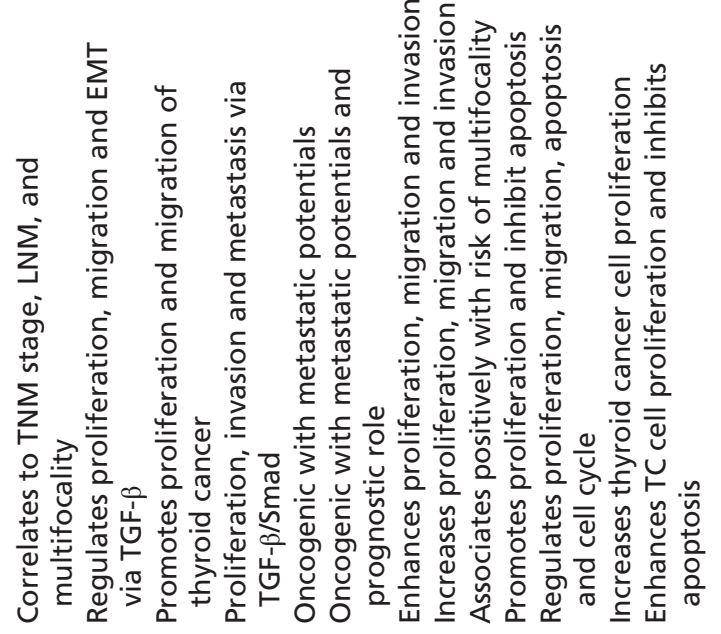

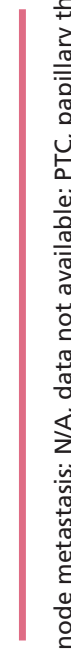

竞|

产<smiles>C=CC=CC</smiles>

巡 突

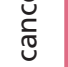

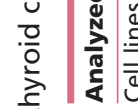

$\varpi$

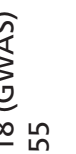

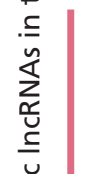

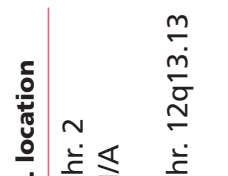

$\stackrel{0}{x}$

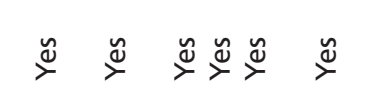

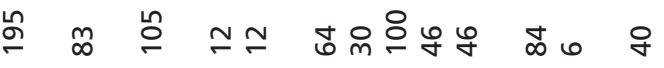

(⿸丆口广

焉

$\stackrel{y}{\circlearrowright} \stackrel{y}{\check{\nu}}$

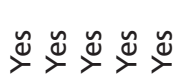

$\stackrel{\tilde{y}}{\check{y}}$
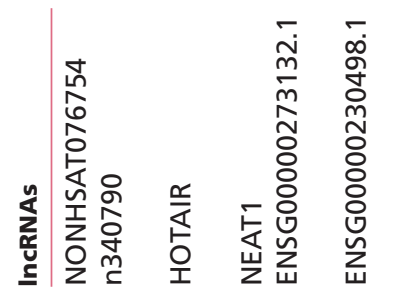

$\frac{\pi}{2}$

๘.

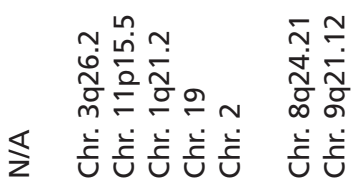

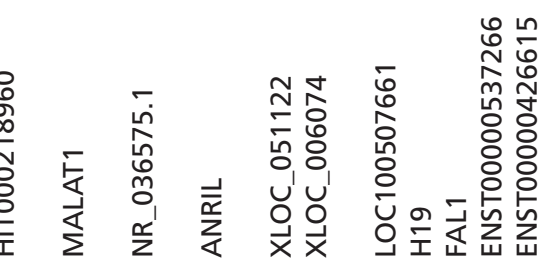

$5 \sum^{5}$ 
resulted in altered phenotypical responses owing to malignant transformation, such as changes in proliferation, cell survival, migration and invasion or apoptosis. This unique feature of lncRNAs opens a new arena for application of lncRNAs as potential therapeutic targets and biomarkers for cancer diagnosis and prognosis.

\section{IncRNAs: therapeutic targets and mechanisms of IncRNA-targeting agents}

\section{IncRNAs are therapeutic targets in thyroid cancer}

High-resolution microarray, genome sequencing and RNA sequencing revealed a massive amount of novel coding and noncoding transcripts which resulted in the identification of abundant ncRNAs, including lncRNAs (Carninci et al. 2005, Trapnell et al. 2010, Agrawal et al. 2014). IncRNAs and their association with cancer have been well summarized (Gutschner \& Diederichs 2012). As a result of state-of-the-art technologies in genomics, epigenomics and transcriptomics, tremendous data has been accumulated and were analyzed to find IncRNAs associated with human cancer (Prensner et al. 2011, Sinicropi et al. 2012). The DNA/RNA sequencing data granted the possibility of characterizing the structure and function of various disease-related SNPs of lncRNAs. The importance of lncRNA-based cancer therapy and the roles of several lncRNAs in cancers have been characterized and strategies targeting them resulted in inhibitory effects on malignant cells in vitro and in vivo (Zhao et al. 2010, Chu et al. 2011, Jin et al. 2011, Wang et al. 2011). Extensive studies were carried out to interrogate the molecular functions of lncRNAs, which resulted in the development of targeting approaches specific to individual lncRNAs (Lee 2012). Advanced RNA sequencing methods also accelerated the progress of developing lncRNA-based cancer management. These findings support the notion that lncRNAs are prospective novel therapeutic targets in cancers. Besides, recent improvements in the development of biological drugs have broadened the types of therapeutic targets and paved way for the development of various novel methodologies to target RNA molecules (Castanotto \& Rossi 2009, Davies et al. 2010). All these methodologies showed a hopeful outcome in cancer inhibition as manifested by RNA-targeted therapeutics in various phases of clinical trials. Taken together, the lncRNAs summarized and discussed above (BANCR, PVT1, ENST00000537266, ENST00000426615, FAL1, H19, LOC100507661，XLOC_051122， XLOC_006074, HIT000218960, ANRIL, NR_036575, MALAT1, HOTAIR,
NONHSAT076754 and NEAT1) and other lncRNAs in Table 2 with oncogenic features could be a potential therapeutic target in thyroid cancer including human cancers and warrant further research on the development of lncRNA-based cancer therapy. Therapeutic agents that potentially target lncRNAs mostly function via reducing the intracellular transcript level of lncRNAs or attenuating their activities and molecular functions in cancer cells. The onco-lncRNAs possess pro-cancerous effects since their expression level or activity is often elevated in cancer cells become druggable targets, although we should not overlook the important tumor-suppressor roles of other lncRNAs in cancer. Therapeutic options which directly target onco-lncRNAs are more likely to have a prominent anticancer effect. At this end, siRNAs and ASOs (antisense oligonucleotides) could easily be used to regulate lncRNA expression and/or function.

\section{Prospective strategies and mechanisms of IncRNA-targeting agents}

IncRNAs are identified to be critically involved in cancer and modulations of their functions have been shown to have promising anticancer effects. As illustrated in Fig. 5, recently, in order to regulate the level of lncRNAs in cancer cells, nucleic acid-based strategies are more frequently employed in targeting lncRNAs either by modifying their structures or mature sequences (Gupta et al. 2010). RNA interference technique have been one of the most relevant methods to target lncRNAs in cancer cells. siRNAs are short, double-stranded RNAs (19-30 nt) which target lncRNA molecules by complementary base pairing. Initially, siRNA duplex unwinds and becomes a linear single-stranded molecule and subsequently assembles into an active RISC (RNA-induced silencing complex). Complementary base pairing to target RNA chops at a single phosphodiester bond found in the middle of the complementary nucleotide sequence to the siRNA (Gupta et al. 2010). Moreover, both siRNAs and shRNAs have been shown to exhibit greater RNA selectivity and knockdown efficiency. The simplicity of siRNA and shRNA synthesis, and versatile design for specific targeting facilitate them as promising therapeutic agents. The stability of these nucleic acid drugs could be greatly improved by various chemical alterations (Geary et al. 2001). ASOs, singlestranded DNAs/RNAs (8-50 nt), are designed specifically for targeting lncRNAs. Generally, ASOs precisely bind to the transcripts of lncRNAs by pairing of complementary nucleotides; the resulting complexes (hybrids) become prey for the intracellular RNase $\mathrm{H} 1$ that chops the 


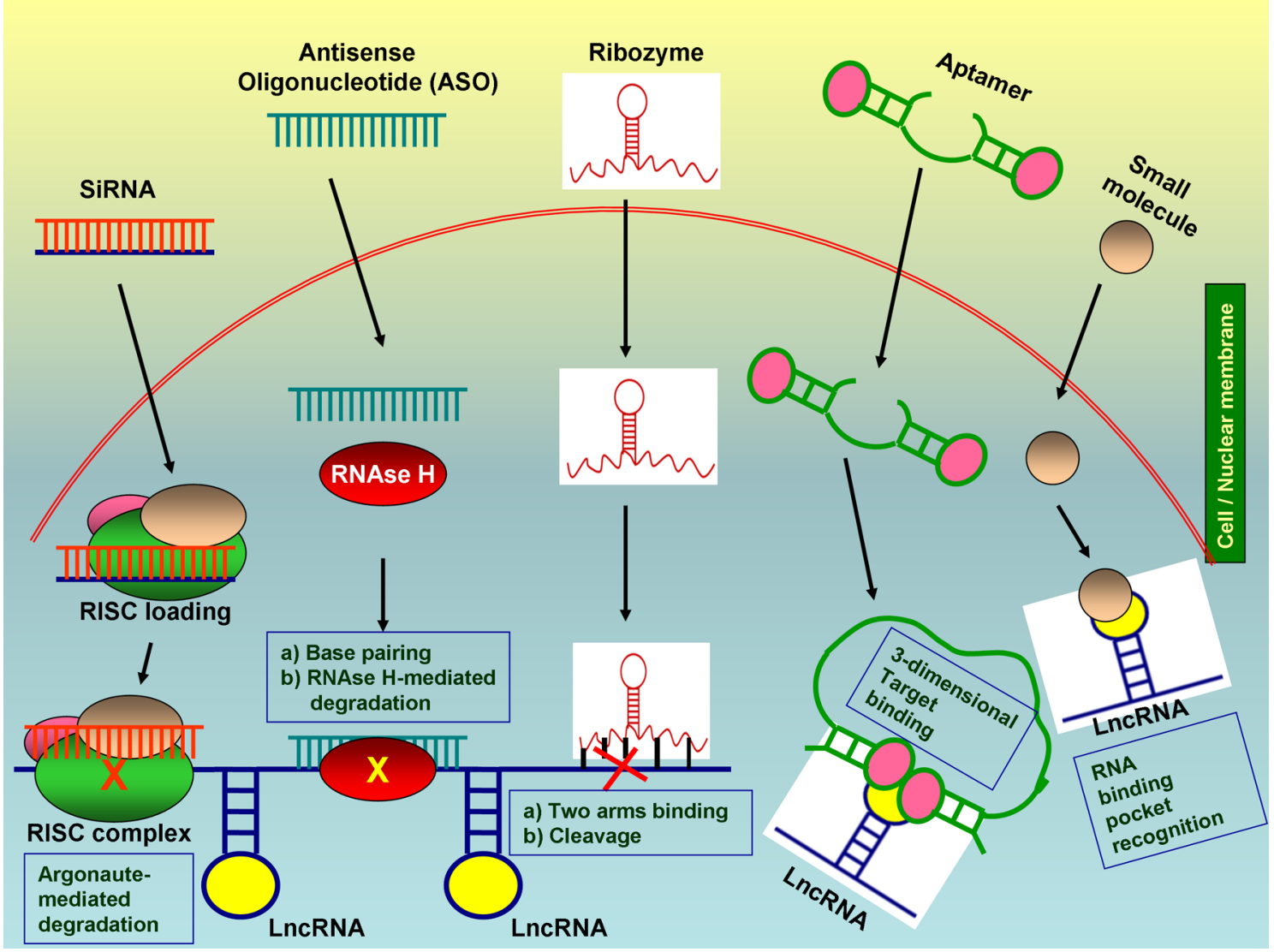

Figure 5

Schematic representation of various IncRNA-targeting agents and their mechanisms. Deregulated IncRNAs in cancer cells are targeted using various molecules such as siRNA, an antisense oligonucleotide, ribozyme, aptamer, small molecules, etc. siRNAs: guide strands initially loaded to AGO2 (argonaute 2) that results in formation of RISC (an active RNA-induced silencing complex). RISC binds to the target RNA by complementary base pairing and cleaves the target RNA. ASOs: RNAse-H identifies the DNA-RNA duplex and cleaves the RNA target. Ribozyme: catalyzes the cleavage of the flanked RNA region downstream to a NUH site via destabilizing the phosphodiester backbone of target RNA. Aptamers: bind to their target IncRNAs specifically fitting to the 3-D structures of IncRNA and suppress the interactions of IncRNAs. Small molecules: specifically bind to the RNA binding pockets of IncRNAs, and compete with protein factors/intracellular small ligands for the binding of IncRNAs. It causes conformational distortion within IncRNA which results in suppression of unique IncRNA. These target-specific molecular agents have an efficient binding capacity and destroy the targeted IncRNAs that exclusively depend on the cellular context. A full colour version of this figure is available at https://doi.org/10.1530/ERC-17-0188.

transcripts of the IncRNAs and they are shown to effectively target lncRNAs in human cancer cells (Gupta et al. 2010, Tripathi et al. 2010). Hammerhead ribozyme is a short, single-stranded catalytic RNA molecule with self-cleavage activity. Under neutral cellular physiological conditions, two of the three flanking helices of the catalytic core make tertiary interactions. Active inhibition of the target lncRNA by the ribozyme is exclusively limited by its base pairing capability. Making an active catalytic motif requires the binding of 2 stems of the ribozyme to the target lncRNAs. After binding, ribozyme catalyzes the cleavage of the flanked RNA region downstream to an NUH site via the destabilization of the phosphodiester backbone of target RNA. Ribozymes have been implicated in targeting lncRNAs in cancer (Pavco et al. 2000). An aptamer represents short DNA or RNA oligonucleotides or peptides which have a stable 3-dimensional (3-D) structure in vivo. They bind to their target IncRNAs specifically fitting to the 3-D structures of lncRNA. Aptamers suppress the interactions of lncRNAs and their critical components and certain distinct characteristics of IncRNAs show advantages over siRNAs (Watrin et al. 2009). On the other hand, small molecules are synthesized to specifically bind to the RNA binding pockets of IncRNAs and compete with protein factors or intracellular small ligands for the binding of lncRNAs. It causes conformational distortion within lncRNA which results in suppression of unique lncRNA (Pushechnikov et al. 2009). Moreover, in cancer treatment, inductions of post-transcriptional processing pathways and miRNAs have also been shown to be valid therapeutic options to suppress lncRNAs (Mimura et al. 2012, Jalali et al. 2013). Developing various innovative 
approaches facilitates the use of combination therapy to augment lncRNA targeting in cancer therapy (Fig. 5).

\section{IncRNAs: diagnostic markers in thyroid cancer}

lncRNAs are potent biomarkers as they do not code for proteins and most of their functions correlate with expression. The expression pattern of lncRNAs is tissuespecific and is greater than the coding mRNAs that enable them to be highly specific diagnostic biomarkers (Derrien et al. 2012). Detection of cancer at the early stages significantly increases the chances of survival. Detection needs robust biomarkers for both invasive and noninvasive methods (sampling of extracellular fluids). For example, circulating nucleic acids (CNAs) are fragments of DNA and RNA molecules found in blood serum and other extracellular fluids. Altered levels of CNAs are associated with tumor and malignant progression, serving as potential tumor biomarkers that could easily be screened by PCR assays (Schwarzenbach et al. 2011). Further ROC curve-mediated analysis of the diagnostic value of NONHSAT076754 revealed that the IncRNA could aid ultrasonography in predicting PTC with LNM (Xia et al. 2017). MALAT1 could serve as a biomarker for thyroid cancer classification and diagnosis (Zhang et al. 2017a). Therefore, these lncRNAs could be used as novel minimally invasive diagnostic and prognostic biomarkers for the assessment of these metastatic PTCs.

Several lncRNAs have been described to be highly specific for a particular cancer type. For example, in thyroid cancer, the level of tumor-suppressive lncRNAs is invariably much lower in malignant tumor tissues when compared to the paired nonneoplastic tissues. The differential expressions of those lncRNAs have also been found to be tissue-specific. Hence, thyroid cancerassociated tumor-suppressive lncRNAs listed in Table 1 could be readily used as diagnostic biomarkers for thyroid cancer (Fig. 2 and Table 1). In addition to the tumor suppressors, oncogenic IncRNAs have also been reported to be tissue-specific and frequently overexpressed in malignant thyroid tumors compared with the paired normal tissues, suggesting that the thyroid cancerassociated oncogenic lncRNAs listed in Table 2 could also be used as a potential diagnostic marker in thyroid cancer (Fig. 3 and Table 2).

In human cancer, several lncRNAs have been characterized as potential biomarkers from human body fluids. Detection of PCA3 in the urine has been shown to be a more specific diagnostic marker in prostate cancer than the other commonly used prostate-specific antigen (Lee et al. 2011). UCA1 (urothelial carcinoma associated 1) transcript detected in urine has been demonstrated to be a sensitive biomarker for bladder carcinoma (Wang et al. 2006). HULC is posed as a promising diagnostic biomarker for hepatocellular carcinoma since it has been detected with high frequency in the plasma of HCC patients (Xie et al. 2013). In oral cancers, a set of lncRNAs in the saliva were identified as potential markers (Tang et al. 2013). Detection of AA174084 in gastric juice was shown to be an indicator of gastric cancer (Shao et al. 2014). Plasmamediated detection of the MALAT1 fragment has been shown to serve as a biomarker for prostate cancer (Ren et al. 2013).

\section{IncRNAs: prognostic markers in thyroid cancer}

lncRNAs have been shown to be aberrantly expressed in cancer and correlate with tumorigenesis, tumor progression and metastasis in various human cancers. IncRNAs could be involved either in oncogenic or tumor-suppressive pathways and their expression may directly correlate with the good/bad prognosis that makes them promising prognostic biomarkers. In thyroid cancer, the expression level of NONHSAT037832 was drastically decreased in PTCs compared with paired normal tissues. A similar pattern was also observed in PTC cell lines (K1 and IHH-4) when compared with the normal Nthy-ori 3-1 cell line. Moreover, downregulated NONHSAT037832 has been significantly associated with LNM and tumor size (larger tumor) suggesting that NONHSAT037832 and rs2439302 of PTCSC 3 could serve as a potential prognostic marker of PTC, as it clearly showed a high value to differentiate between PTCs and noncancerous tissues (Lan et al. 2015b). The rs2439302 of PTCSC3 has also been associated with LNM and tumor multifocality reflecting a pivotal role in clinical course (Jendrzejewski et al. 2016). Besides, LOC100507661 has been frequently detected as a highly expressed lncRNA in PTC and ATC cases, and significantly associated with LNM and the classical BRAF mutation (Kim et al. 2016). NR_036575.1 and FAL1 have been positively associated with extra thyroidal extension (ETE) and tumor size, and the risk of multifocality, respectively (Jeong et al. 2016, Sun et al. 2016). XLOC_051122 and XLOC_006074 have also been demonstrated to correlate with LNM especially in patients carrying wild-type $B R A F$ and shown to be overexpressed in these cases and associated with risk factors of adverse prognosis (Liyanarachchi et al. 2016). Similarly, NONHSAT076747 and NONHSAT122730 


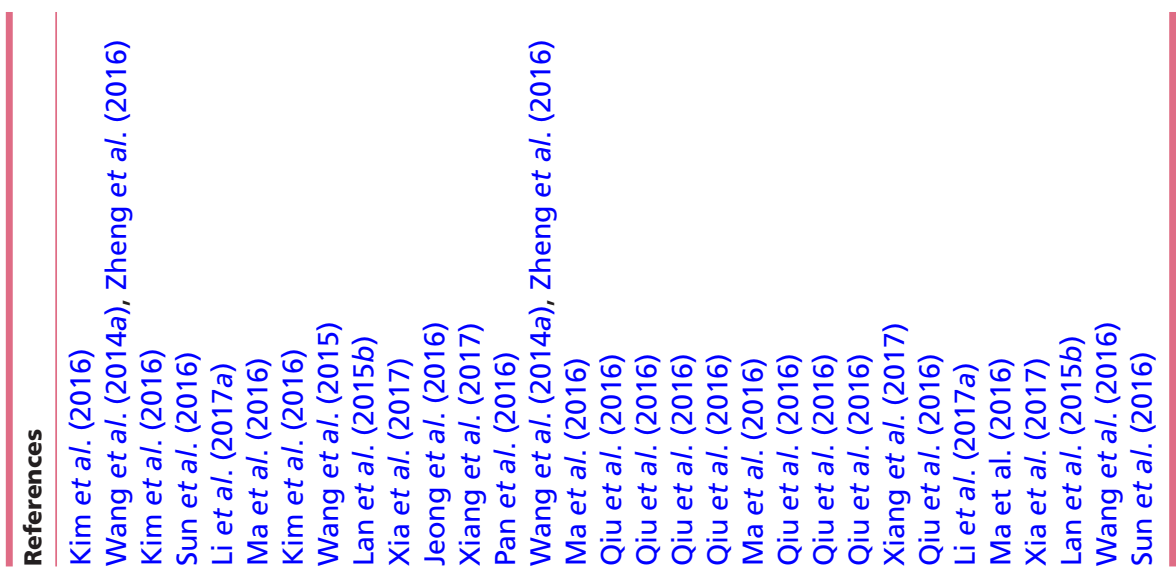

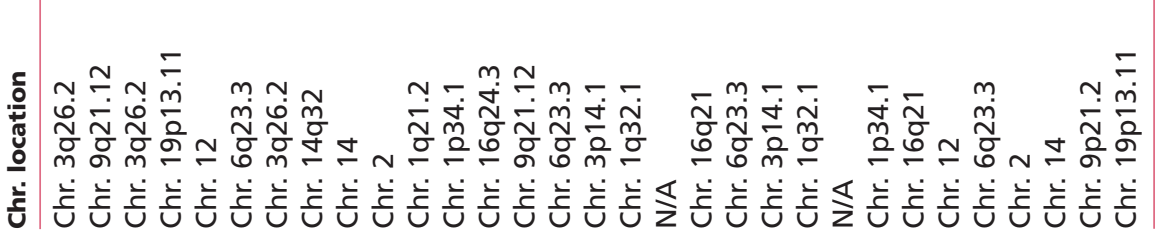
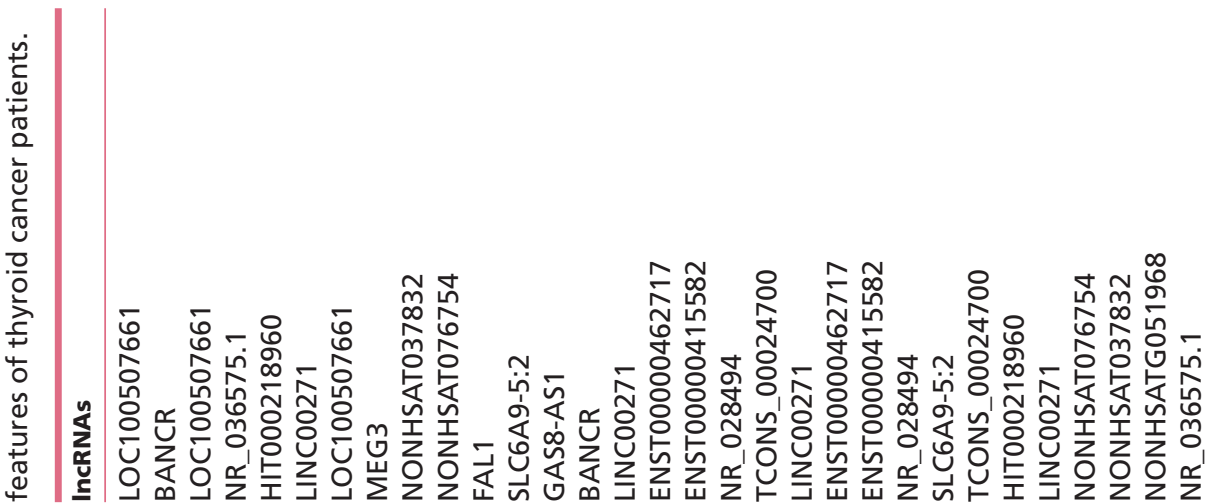

.

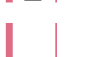

ब

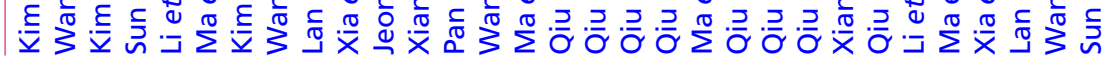

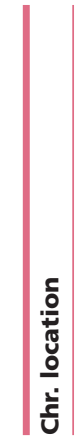

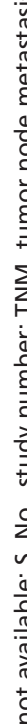

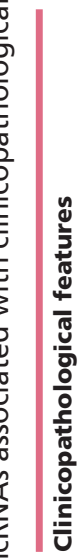

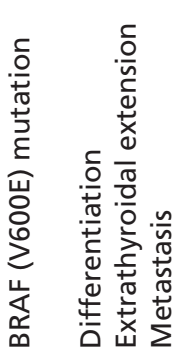
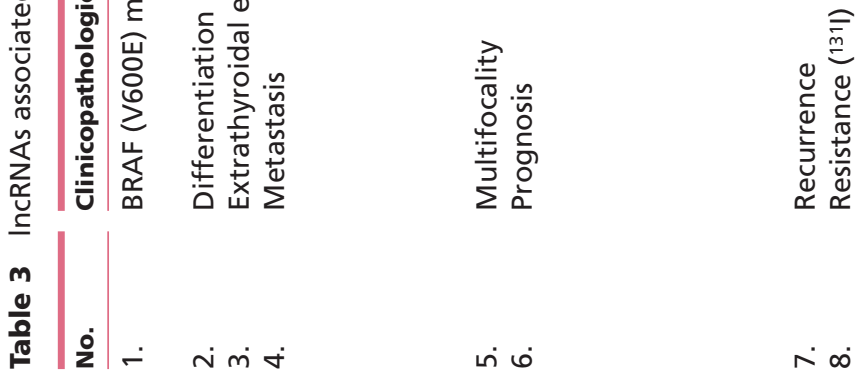

เก่

$\sim \infty$
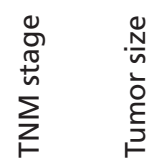

๖ั

a

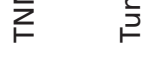


expression have also been associated with $L M N$ and hence could serve as potent prognostic biomarkers in thyroid cancer (Wang et al. 2016). A study explored plasma lncRNAs using lncRNA microarray chip as a novel biomarker panel for the diagnosis of non-131I-avid lung metastases of PTCs. In the non-131 I-avid lung metastases of PTC cases, two IncRNAs (ENST00000462717 and ENST00000415582) were discovered to be overexpressed, while two (TCONS_00024700 and NR_028494) were downregulated. Low (ENST00000462717 and ENST00000415582) and high lncRNA levels in plasma (TCONS_00024700 and NR_028494) have been associated with better prognosis of these PTC cases. ROC-mediated analysis of these 4 lncRNAs revealed that they have high diagnostic specificity and sensitivity for predicting non-131I-avid lung metastases of PTC (Qiu et al. 2016). Furthermore, PTCSC1 and PTCSC2 were associated with thyroid cancer risk (He et al. 2009, Wang et al. 2017). HOTAIR overexpression has been associated with poor outcome (Li et al. 2017b). LINC00271 and HIT000218960 have been associated with ETE, LNM, TNM stage III \& IV and recurrence (Ma et al. 2016, Li et al. 2017a). A recent study found that expression of SLC6A9-5:2 have been significantly decreased in 131 I-resistant thyroid cancer cell lines and ${ }^{131}$ I-insensitive patients and were positively correlated with the expression of PARP-1. Artificial knockdown of SLC6A9 or inhibiting PARP-1 in the sensitive PTC cell lines resulted in a resistant phenotype under ${ }^{131}$ I exposure. In turn, SLC6A9-5:2 overexpression restored the sensitivity. Furthermore, the SLC6A9 low expression has been associated with poor prognosis of PTCs, suggesting that this lncRNA could be a prognostic biomarker (Xiang et al. 2017). Therefore, the lncRNAs discussed above including those listed in Table 3 could readily serve as a valuable prognostic marker in PTC cases as they were significantly associated with various clinical and pathological features (Table 3).

\section{Conclusion and future perspectives}

Understanding the mechanism of lncRNAs and their role is important not only to normal thyroid tissues but also in thyroid cancer and its disease stages. Various high-throughput next-generation genomic technologies facilitated the rapid screening of tissue-specific differentially expressed lncRNA transcripts. From the above-discussed studies, it is evident that lncRNAs are emerging as a new class of ncRNAs with a significant and crucial role in thyroid cell proliferation, carcinogenesis and metastasis. These differentially expressed IncRNAs play a pivotal role either as a tumor suppressor or as an oncogene. The oncogenic IncRNAs could be molecular therapeutic targets. The tumor-suppressive and oncogenic lncRNAs may serve as potential diagnostic biomarkers, while the disease-associated lncRNAs listed in Table 3 could serve as prognostic biomarkers. Many differentially expressed IncRNAs are understudied and they need further in vitro and in vivo functional studies to investigate their functions and contribution to thyroid cancer pathogenesis. The function of lncRNAs could be initially predicted by various in silico analysis tools. Based on these predictions, siRNA, shRNA, small molecule and ASO-mediated inhibition of target lncRNA and overexpression of a mammalian expression vector with the cDNA of a target lncRNA in vitro are valid methodologies for loss-of-function and gain-offunction studies, respectively. Phenotypic assays such as proliferation, cell death or apoptosis, cell cycle, migration, invasion and metastasis and immunoblotting for detecting signaling network can be performed upon implementing transient/stable in vitro methodologies. Xenograft tumor on nude mice and knockout mice are functional in vivo animal models and these experimental methods could determine the functions of hundreds of uncharacterized differentially expressed IncRNAs in thyroid cancer. Moreover, translation of lncRNAs from bench to bedside warrants a thorough and detailed study of their structure, and their regulation in normal and malignant cells, large case-control studies and possible side effects and rectifying methods upon gene therapy. Although many groups have studied lncRNAs in thyroid cancer, the majority of them have focused only on PTC. On the other hand, to date, other follicular cell-derived thyroid cancer subtypes have not been studied apart from LOC100507661 in two ATC cell lines (C643 and 8505C) (Kim et al. 2016). There are many areas which are less studied: for example, subtypes of PTCs (tall cell-PTC and follicular variant PTC), FTC and ATC. Further studies in these areas may not only advance the understanding of molecular pathogenesis of these subtypes but may also improve the therapeutic, diagnostic and prognostic options of these subtypes including ATC, the most deadly thyroid cancer subtype.

\section{Declaration of interest}

The authors declare that there is no conflict of interest that could be perceived as prejudicing the impartiality of this review. 


\section{Funding}

This work did not receive any specific grant from any funding agency in the public, commercial or not-for-profit sector.

\section{Acknowledgements}

The authors sincerely thank all the researchers in this field whose valuable research provided them delightful reading experience that enabled them to write this review. The authors apologize to all their colleagues whose work could not be cited owing to space constraints.

\section{References}

Agrawal N, Akbani R, Aksoy BA, Ally A, Arachchi H, Asa SL, Auman JT, Balasundaram M, Balu S, Baylin SB, et al. 2014 Integrated genomic characterization of papillary thyroid carcinoma. Cell 159 676-690. (https://doi.org/10.1016/j.cell.2014.09.050)

Arunkumar G, Murugan AK, Srinivasa Rao HP, Subbiah S, Rajaraman R \& Munirajan AK 2017 Long non-coding RNA CCAT1 is overexpressed in oral squamous cell carcinomas and predicts poor prognosis. Biomedical Reports 6 455-462. (https://doi.org/10.3892/ br.2017.876)

Bozgeyik E, Igci YZ, Sami Jacksi MF, Arman K, Gurses SA, Bozgeyik I, Pala E, Yumrutas O, Temiz E \& Igci M 2016 A novel variable exonic region and differential expression of LINC00663 non-coding RNA in various cancer cell lines and normal human tissue samples. Tumour Biology 37 8791-8798. (https://doi.org/10.1007/s13277-015-4782-3)

Bussemakers MJ, van Bokhoven A, Verhaegh GW, Smit FP, Karthaus HF, Schalken JA, Debruyne FM, Ru N \& Isaacs WB 1999 DD3: a new prostate-specific gene, highly overexpressed in prostate cancer. Cancer Research 59 5975-5979.

Carninci P, Kasukawa T, Katayama S, Gough J, Frith MC, Maeda N, Oyama R, Ravasi T, Lenhard B, Wells C, et al. 2005 The transcriptional landscape of the mammalian genome. Science 309 1559-1563. (https://doi.org/10.1126/science.1112014)

Castanotto D \& Rossi JJ 2009 The promises and pitfalls of RNAinterference-based therapeutics. Nature $\mathbf{4 5 7}$ 426-433. (https://doi. org/10.1038/nature07758)

Chu C, Qu K, Zhong FL, Artandi SE \& Chang HY 2011 Genomic maps of long noncodingRNA occupancy reveal principles of RNAchromatin interactions. Molecular Cell 44 667-678. (https://doi. org/10.1016/j.molcel.2011.08.027)

Chung S, Nakagawa H, Uemura M, Piao L, Ashikawa K, Hosono N, Takata R, Akamatsu S, Kawaguchi T, Morizono T, et al. 2011 Association of a novel long non-coding RNA in 8q24 with prostate cancer susceptibility. Cancer Science 102 245-252. (https://doi. org/10.1111/j.1349-7006.2010.01737.x)

Cooper DS 2009 Revised American Thyroid Association management guidelines for patients with thyroid nodules and differentiated thyroid cancer. Thyroid 19 1167-1214. (https://doi.org/10.1089/ thy.2009.0110)

DeLellis RA, Lloyd RV, Heitz PU \& Eng C 2004 World Health Organization Classification of Tumours. Pathology and Genetics of Tumors of Endocrine Organs. Lyon, France: IARC Press.

Derrien T, Johnson R, Bussotti G, Tanzer A, Djebali S, Tilgner H, Guernec G, Martin D, Merkel A, Knowles DG, et al. 2012 The GENCODE v7 catalog of human long noncoding RNAs: analysis of their gene structure, evolution, and expression. Genome Research 22 1775-1789. (https://doi.org/10.1101/gr.132159.111)

Du Y, Xia W, Zhang J, Wan D, Yang Z \& Li X 2017 Comprehensive analysis of long noncoding RNA-mRNA co-expression patterns in thyroid cancer. Molecular Biosystems 13 2107-2115. (https://doi. org/10.1039/c7mb00375g)
Fagin JA \& Wells SA Jr 2016 Biologic and clinical perspectives on thyroid cancer. New England Journal of Medicine 375 1054-1067. (https://doi.org/10.1056/NEJMra1501993)

Fan M, Li X, Jiang W, Huang Y, Li J \& Wang Z 2013 A long non-coding RNA, PTCSC3, as a tumor suppressor and a target of miRNAs in thyroid cancer cells. Experimental and Therapeutic Medicine 5 1143-1146. (https://doi.org/10.3892/etm.2013.933)

Geary RS, Watanabe TA, Truong L, Freier S, Lesnik EA, Sioufi NB, Sasmor H, Manoharan M \& Levin AA 2001 29-O-(2-Methoxyethyl)modified antisense oligonucleotides following intraduodenalinstillation in rats. Journal of Pharmacology and Experimental Therapeutics 296 890-897.

Goedert L, Plaça JR, Fuziwara CS, Machado MCR, Plaça DR, Almeida PP, Sanches TP, Santos JFD, Corveloni AC, Pereira IEG, et al. 2017 Identification of long noncoding RNAs deregulated in papillary thyroid cancer and correlated with BRAFV600E mutation by bioinformatics integrative analysis. Scientific Reports 7 1662. (https:// doi.org/10.1038/s41598-017-01957-0)

Grant CS 2015 Recurrence of papillary thyroid cancer after optimized surgery. Gland Surgery 4 52-62.

Grieco M, Santoro M, Berlingieri MT, Melillo RM, Donghi R, Bongarzone I, Pierotti MA, Della Porta G, Fusco A \& Vecchio G 1990 PTC is a novel rearranged form of the ret proto-oncogene and is frequently detected in vivo in human thyroid papillary carcinomas. Cell 60 557-563. (https://doi.org/10.1016/0092-8674(90)90659-3)

Gudmundsson J, Sulem P, Gudbjartsson DF, Jonasson JG, Sigurdsson A, Bergthorsson JT, He H, Blondal T, Geller F, Jakobsdottir M, et al. 2009 Common variants on $9 \mathrm{q} 22.33$ and $14 \mathrm{q} 13.3$ predispose to thyroid cancer in European populations. Nature Genetics 41 460-464. (https://doi.org/10.1038/ng.339)

Gudmundsson J, Sulem P, Gudbjartsson DF, Jonasson JG, Masson G, He H, Jonasdottir A, Sigurdsson A, Stacey SN, Johannsdottir H, et al. 2012 Discovery of common variants associated with low TSH levels and thyroid cancer risk. Nature Genetics 44 319-322. (https://doi. org/10.1038/ng.1046)

Gupta RA, Shah N, Wang KC, Kim J, Horlings HM, Wong DJ, Tsai MC, Hung T, Argani P, Rinn JL, et al. 2010 Long non-coding RNA HOTAIR reprograms chromatin state to promote cancer metastasis. Nature 464 1071-1076. (https://doi.org/10.1038/nature08975)

Gutschner T \& Diederichs S 2012 The hallmarks of cancer: a long noncoding RNA point of view. RNA Biology 9 703-719. (https://doi. org/10.4161/rna.20481)

He H, Nagy R, Liyanarachchi S, Jiao H, Li W, Suster S, Kere J \& de la Chapelle A 2009 A susceptibility locus for papillary thyroid carcinoma on chromosome 8q24. Cancer Research 69 625-631. (https://doi.org/10.1158/0008-5472.CAN-08-1071)

He H, Li W, Liyanarachchi S, Jendrzejewski J, Srinivas M, Davuluri RV, Nagy R \& de la Chapelle A 2015 Genetic predisposition to papillary thyroid carcinoma: involvement of FOXE1, TSHR, and a novel lincRNA gene, PTCSC2. Journal of Clinical Endocrinology and Metabolism 100 E164-E172. (https://doi.org/10.1210/jc.2014-2147)

Hemerly JP, Bastos AU \& Cerutti JM 2010 Identification of several novel non-p.R132 IDH1 variants in thyroid carcinomas. European Journal Endocrinology 163 747-755. (https://doi.org/10.1530/EJE-100473)

Hou P, Liu D, Shan Y, Hu S, Studeman K, Condouris S, Wang Y, Trink A, El-Naggar AK, Tallini G, Vasko V \& Xing M. 2007 Genetic alterations and their relationship in the phosphatidylinositol 3-kinase/Akt pathway in thyroid cancer. Clinical Cancer Research 13 1161-1170. (https://doi.org/10.1158/1078-0432.CCR-06-1125)

Howlader N, Noone AM, Krapcho M, Miller D, Bishop K, Kosary CL, Yu M, Ruhl J, Tatalovich Z, Mariotto A, et al. 2017 SEER Cancer Statistics Review, 1975-2014, National Cancer Institute. Bethesda, MD, USA. (available at: https://seer.cancer.gov/csr/1975_2014/)

Hu X, Feng Y, Zhang D, Zhao SD, Hu Z, Greshock J, Zhang Y, Yang L, Zhong X, Wang LP, et al. 2014 A functional genomic approach 
identifies FAL1 as an oncogenic long noncoding RNA that associates with BMI1 and represses p21 expression in cancer. Cancer Cell 26 344-357. (https://doi.org/10.1016/j.ccr.2014.07.009)

Huarte M 2015 The emerging role of IncRNAs in cancer. Nature Medicine 21 1253-1261. (https://doi.org/10.1038/nm.3981)

Huang JK, Ma L, Song WH, Lu BY, Huang YB, Dong HM, Ma XK, Zhu ZZ \& Zhou R 2016 MALAT1 promotes the proliferation and invasion of thyroid cancer cells via regulating the expression of IQGAP1. Biomedicine and Pharmacotherapy 83 1-7.

Jalali S, Bhartiya D, Lalwani MK, Sivasubbu S \& Scaria V 2013 Systematic transcriptome wide analysis of lncRNA-miRNA interactions. PLoS ONE 8 e53823. (https://doi.org/10.1371/journal.pone.0053823)

Jendrzejewski J, He H, Radomska HS, Li W, Tomsic J, Liyanarachchi S, Davuluri RV, Nagy R \& de la Chapelle A 2012 The polymorphism rs 944289 predisposes to papillary thyroid carcinoma through a large intergenic noncoding RNA gene of tumor suppressor type. PNAS 109 8646-8651. (https://doi.org/10.1073/pnas.1205654109)

Jendrzejewski J, Thomas A, Liyanarachchi S, Eiterman A, Tomsic J, He H, Radomska HS, Li W, Nagy R, Sworczak K \& de la Chapelle A 2015 PTCSC3 is involved in papillary thyroid carcinoma development by modulating S100A4 gene expression. Journal of Clinical Endocrinology and Metabolism 100 E1370-E1377. (https://doi.org/10.1210/jc.20152247)

Jendrzejewski J, Liyanarachchi S, Nagy R, Senter L, Wakely PE, Thomas A, Nabhan F, He H, Li W, Sworczak K, et al. 2016 Papillary thyroid carcinoma: association between germline DNA variant markers and clinical parameters. Thyroid 26 1276-1284. (https://doi. org/10.1089/thy.2015.0665)

Jeong S, Lee J, Kim D, Seol MY, Lee WK, Jeong JJ, Nam KH, Jung SG, Shin DY, Lee EJ, et al. 2016 Relationship of focally amplified long noncoding on chromosome 1 (FAL1) lncRNA with E2F transcription factors in thyroid cancer. Medicine 95 e2592. (https://doi. org/10.1097/MD.0000000000002592)

Jin G, Sun J, Isaacs SD, Wiley KE, Kim ST, Chu LW, Zhang Z, Zhao H, Zheng SL, Isaacs WB, et al. 2011 Human polymorphisms at long non-coding RNAs (lncRNAs) and association with prostate cancer risk. Carcinogenesis 32 1655-1659. (https://doi.org/10.1093/carcin/ bgr187)

Kentwell J, Gundara JS \& Sidhu SB 2014 Noncoding RNAs in endocrine malignancy. Oncologist 19 483-491. (https://doi.org/10.1634/ theoncologist.2013-0458)

Kim D, Lee WK, Jeong S, Seol MY, Kim H, Kim KS, Lee EJ, Lee J \& Jo YS 2016 Upregulation of long noncoding RNA LOC100507661 promotes tumor aggressiveness in thyroid cancer. Molecular and Cellular Endocrinology 431 36-45. (https://doi.org/10.1016/j. mce.2016.05.002)

Lan X, Zhang H, Wang Z, Dong W, Sun W, Shao L, Zhang T \& Zhang D $2015 a$ Genome-wide analysis of long noncoding RNA expression profile in papillary thyroid carcinoma. Gene 569 109-117. (https:// doi.org/10.1016/j.gene.2015.05.046)

Lan X, Sun W, Zhang P, He L, Dong W, Wang Z, Liu S \& Zhang H $2015 b$ Downregulation of long noncoding RNA NONHSAT037832 in papillary thyroid carcinoma and its clinical significance. Tumour Biology 37 6117-6123. (https://doi.org/10.1007/s13277. 015-4461-4)

Landa I, Ganly I, Chan TA, Mitsutake N, Matsuse M, Ibrahimpasic T, Ghossein RA \& Fagin JA 2013 Frequent somatic TERT promoter mutations in thyroid cancer: higher prevalence in advanced forms of the disease. Journal of Clinical Endocrinology and Metabolism 98 E1562-E1566. (https://doi.org/10.1210/jc.2013-2383)

Landa I, Ibrahimpasic T, Boucai L, Sinha R, Knauf JA, Shah RH, Dogan S, Ricarte-Filho JC, Krishnamoorthy GP, Xu B, et al. 2016 Genomic and transcriptomic hallmarks of poorly differentiated and anaplastic thyroid cancers. Journal of Clinical Investigation 126 1052-1066. (https://doi.org/10.1172/JCI85271)
Lee JT 2012 Epigenetic regulation by long noncoding RNAs. Science 338 1435-1439. (https://doi.org/10.1126/science.1231776)

Lee GL, Dobi A \& Srivastava S 2011 Prostate cancer: diagnostic performance of the PCA3 urine test. Nature Review of Urology $\mathbf{8}$ 123-124. (https://doi.org/10.1038/nrurol.2011.10)

Li X \& Wang Z 2012 The role of noncoding RNA in thyroid cancer. Gland Surgery 1 146-150.

Li T, Yang XD, Ye CX, Shen ZL, Yang Y, Wang B, Guo P, Gao ZD, Ye YJ, Jiang KW, et al. 2017 a Long noncoding RNA HIT000218960 promotes papillary thyroid cancer oncogenesis and tumor progression by upregulating the expression of high mobility group AT-hook 2 (HMGA2) gene. Cell Cycle 16 224-231. (https://doi.org/10 $.1080 / 15384101.2016 .1261768)$

Li HM, Yang H, Wen DY, Luo YH, Liang CY, Pan DH, Ma W, Chen G, He Y \& Chen JQ $2017 b$ Overexpression of LncRNA HOTAIR is associated with poor prognosis in thyroid carcinoma: a study based on TCGA and GEO data. Hormone Metabolism Research 49 388-399. (https://doi.org/10.1055/s-0043-103346)

Li JH, Zhang SQ, Qiu XG, Zhang SJ, Zheng SH \& Zhang DH 2017c Long non-coding RNA NEAT1 promotes malignant progression of thyroid carcinoma by regulating miRNA-214. International Journal of Oncology 50 708-716. (https://doi.org/10.3892/ijo.2016.3803)

Li Q, Shen W, Li X, Zhang L \& Jin X 2017d The lncRNA n340790 accelerates carcinogenesis of thyroid cancer by regulating miR-1254. American Journal of Translational Research 9 2181-2194.

Li Q, Li H, Zhang L, Zhang C, Yan W \& Wang C 2017e Identification of novel long non-coding RNA biomarkers for prognosis prediction of papillary thyroid cancer. Oncotarget 8 46136-46144.

Li Z, Gao B, Hao S, Tian W, Chen Y, Wang L, Zhang X \& Luo D $2017 f$ Knockdown of lncRNA-PANDAR suppresses the proliferation, cell cycle and promotes apoptosis in thyroid cancer cells. EXCLI Journal 16 354-362.

Liao T, Qu N, Shi RL, Guo K, Ma B, Cao YM, Xiang J, Lu ZW, Zhu YX, Li DS, et al. 2017 BRAF-activated LncRNA functions as a tumor suppressor in papillary thyroid cancer. Oncotarget 8 238-247.

Liu Z, Hou P, Ji M, Guan H, Studeman K, Jensen K, Vasko V, El-Naggar AK \& Xing M 2008 Highly prevalent genetic alterations in receptor tyrosine kinases and phosphatidylinositol 3-kinase/ akt and mitogen-activated protein kinase pathways in anaplastic and follicular thyroid cancers. Journal of Clinical Endocrinology and Metabolism 93 3106-3116. (https://doi.org/10.1210/jc.2008-0273)

Liu Y, Pan S, Liu L, Zhai X, Liu J, Wen J, Zhang Y, Chen J, Shen H \& $\mathrm{Hu} \mathrm{Z} 2012$ A genetic variant in long non-coding RNA HULC contributes to risk of HBV-related hepatocellular carcinoma in a Chinese population. PLOS ONE 7 e35145. (https://doi.org/10.1371/ journal.pone.0035145)

Liu D, Yang C, Bojdani E, Murugan AK \& Xing M 2013a Identification of RASAL1 as a major tumor suppressor gene in thyroid cancer. Journal of the National Cancer Institute 105 1617-1627. (https://doi. org/10.1093/jnci/djt249)

Liu X, Bishop J, Shan Y, Pai S, Liu D, Murugan AK, Sun H, El-Naggar AK \& Xing M 2013b Highly prevalent TERT promoter mutations in aggressive thyroid cancers. Endocrine-Related Cancer 20 603-610. (https://doi.org/10.1530/ERC-13-0210)

Liu X, Qu S, Liu R, Sheng C, Shi X, Zhu G, Murugan AK, Guan H, Yu H, Wang Y, et al. 2014 TERT promoter mutations and their association with BRAF V600E mutation and aggressive clinicopathological characteristics of thyroid cancer. Journal of Clinical Endocrinology and Metabolism 99 E1130-E1136. (https://doi.org/10.1210/jc.2013-4048)

Liu L, Yang J, Zhu X, Li D, Lv Z \& Zhang X. 2016 Long noncoding RNA H19 competitively binds miR-17-5p to regulate YES1 expression in thyroid cancer. FEBS Journal 283 2326-2329. (https://doi. org/10.1111/febs.13741)

Liyanarachchi S, Li W, Yan P, Bundschuh R, Brock P, Senter L, Ringel MD, de la Chapelle A \& He H 2016 Genome-wide expression http://erc.endocrinology-journals.org https://doi.org/10.1530/ERC-17-0188
(2) 2018 Society for Endocrinology Published by Bioscientifica Ltd. Printed in Great Britain 
screening discloses long noncoding RNAs involved in thyroid carcinogenesis. Journal of Clinical Endocrinology and Metabolism 101 4005-4013. (https://doi.org/10.1210/jc.2016-1991)

Ma B, Liao T, Wen D, Dong C, Zhou L, Yang S, Wang Y \& Ji Q 2016 Long intergenic non-coding RNA 271 is predictive of a poorer prognosis of papillary thyroid cancer. Scientific Reports 636973 (https://doi.org/10.1038/srep36973)

Masago K, Asato R, Fujita S, Hirano S, Tamura Y, Kanda T, Mio T, Katakami N, Mishima M \& Ito J 2009 Epidermal growth factor receptor gene mutations in papillary thyroid carcinoma. International Journal of Cancer 124 2744-2749. (https://doi.org/10.1002/ijc.24250)

Matouk IJ, Abbasi I, Hochberg A, Galun E, Dweik H \& Akkawi M 2009 Highly upregulated in liver cancer noncoding RNA is overexpressed in hepatic colorectal metastasis. European Journal of Gastroenterology and Hepatology 21 688-692.

Mimura N, Fulciniti M, Gorgun G, Tai YT, Cirstea D, Santo L, Hu Y, Fabre C, Minami J, Ohguchi H, et al. 2012 Blockade of XBP1 splicing by inhibition of IRE1 is a promising therapeutic option in multiple myeloma. Blood 119 5772-5781. (https://doi.org/10.1182/blood2011-07-366633)

Mitsiades CS, Kotoula V, Poulaki V, Sozopoulos E, Negri J, Charalambous E, Fanourakis G, Voutsinas G, Tseleni-Balafouta S \& Mitsiades N 2006 Epidermal growth factor receptor as a therapeutic target in human thyroid carcinoma: mutational and functional analysis. Journal of Clinical Endocrinology and Metabolism 91 3662-3666. (https://doi.org/10.1210/jc.2006-0055)

Murugan AK \& Xing M 2011 Anaplastic thyroid cancers harbor novel oncogenic mutations of the ALK gene. Cancer Research $\mathbf{7 1}$ 4403-4411. (https://doi.org/10.1158/0008-5472.CAN-10-4041)

Murugan AK, Dong J, Xie J \& Xing M 2009 MEK1 mutations, but not ERK2 mutations, occur in melanomas and colon carcinomas, but none in thyroid carcinomas. Cell Cycle 8 2122-2124. (https://doi. org/10.4161/cc.8.13.8710)

Murugan AK, Bojdani E \& Xing M 2010 Identification and functional characterization of isocitrate dehydrogenase 1 (IDH1) mutations in thyroid cancer. Biochemical and Biophysical Research Communications 393 555-559. (https://doi.org/10.1016/j.bbrc.2010.02.095)

Murugan AK, Dong J, Xie J \& Xing M 2011 Uncommon GNAQ, MMP8, AKT3, EGFR, and PIK3R1 mutations in thyroid cancers. Endocrine Pathology 22 97-102. (https://doi.org/10.1007/s12022011-9155-x)

Murugan AK, Humudh EA, Qasem E, Al-Hindi H, Almohanna M, Hassan ZK \& Alzahrani AS 2015a Absence of somatic mutations of the mTOR gene in differentiated thyroid cancer. Meta Gene 6 69-71. (https://doi.org/10.1016/j.mgene.2015.08.005)

Murugan AK, Munirajan AK \& Alzahrani AS 2015 $b$ MicroRNAs: modulators of the Ras oncogenes in oral cancer. Journal of Cellular Physiology 231 1424-1431. (https://doi.org/10.1002/jcp.25269)

Murugan AK, Qasem E, Al-Hindi H, Shi Y \& Alzahrani AS 2016 Classical V600E and other non-hotspot BRAF mutations in adult differentiated thyroid cancer. Journal of Translational Medicine 14204. (https://doi.org/10.1186/s12967-016-0958-x)

Nikiforova MN, Lynch RA, Biddinger PW, Alexander EK, Dorn GW 2nd, Tallini G, Kroll TG \& Nikiforov YE 2003 RAS point mutations and PAX8-PPAR gamma rearrangement in thyroid tumors: evidence for distinct molecular pathways in thyroid follicular carcinoma. Journal of Clinical Endocrinology and Metabolism 88 2318-2326. (https://doi. org/10.1210/jc.2002-021907)

Pan W, Zhou L, Ge M, Zhang B, Yang X, Xiong X, Fu G, Zhang J, Nie X, Li H, et al. 2016 Whole exome sequencing identifies IncRNA GAS8-AS1 and LPAR4 as novel papillary thyroid carcinoma driver alternations. Human Molecular Genetics 25 1875-1884. (https://doi. org/10.1093/hmg/ddw056)

Pacini F \& Castagna MG 2012 Approach to and treatment of differentiated thyroid carcinoma. Medical Clinics of North America 96 369-383. (https://doi.org/10.1016/j.mcna.2012.01.002)
Panzitt K, Tschernatsch MM, Guelly C, Moustafa T, Stradner M, Strohmaier HM, Buck CR, Denk H, Schroeder R, Trauner M, et al. 2007 Characterization of HULC, a novel gene with striking up-regulation in hepatocellular carcinoma, as noncoding RNA. Gastroenterology 132 330-342. (https://doi.org/10.1053/j. gastro.2006.08.026)

Pavco PA, Bouhana KS, Gallegos AM, Agrawal A, Blanchard KS, Grimm SL, Jensen KL, Andrews LE, Wincott FE, Pitot PA, et al. 2000 Antitumor and antimetastatic activity of ribozymes targeting the messenger RNA of vascular endothelial growth factor receptors. Clinical Cancer Research 6 2094-2103.

Petrovics G, Zhang W, Makarem M, Street JP, Connelly R, Sun L, Sesterhenn IA, Srikantan V, Moul JW \& Srivastava S 2004 Elevated expression of PCGEM1, a prostate-specific gene with cell growthpromoting function, is associated with high-risk prostate cancer patients. Oncogene 23 605-611. (https://doi.org/10.1038/sj. onc.1207069)

Prensner JR, Iyer MK, Balbin OA, Dhanasekaran SM, Cao Q, Brenner JC, Laxman B, Asangani IA, Grasso CS, Kominsky HD, et al. 2011 Transcriptome sequencing across a prostate cancer cohort identifies PCAT-1, anunannotated lincRNA implicated in disease progression. Nature Biotechnology 29 742-749. (https://doi.org/10.1038/nbt.1914)

Pushechnikov A, Lee MM, Childs-Disney JL, Sobczak K, French JM, Thornton CA \& Disney MD 2009 Rational design of ligands targeting triplet repeating transcripts that cause RNA dominant disease: application to myotonic muscular dystrophy type 1 and spinocerebellar ataxia type 3. Journal of the American Chemical Society 131 9767-9779. (https://doi.org/10.1021/ja9020149)

Qasem E, Murugan AK, Al-Hindi H, Xing M, Almohanna M, Alswailem M \& Alzahrani AS 2015 TERT promoter mutations in thyroid cancer: a report from a Middle Eastern population. Endocrine Related Cancer 22 901-908. (https://doi.org/10.1530/ERC-15-0396)

Qiu ZL, Shen CT, Sun ZK, Wei WJ, Zhang XY, Song HJ \& Luo QY 2016 Circulating long non-coding RNAs act as biomarkers for predicting 131I uptake and mortality in papillary thyroid cancer patients with lung metastases. Cellular Physiology and Biochemistry 40 1377-1390.

Ren S, Wang F, Shen J, Sun Y, Xu W, Lu J, Wei M, Xu C, Wu C, Zhang Z, et al. 2013 Long noncoding RNA metastasis associated in lung adenocarcinoma transcript 1derived miniRNA as a novel plasma-based biomarker for diagnosing prostate cancer. European Journal of Cancer 49 2949-2959. (https://doi.org/10.1016/j. ejca.2013.04.026)

Ricarte-Filho JC, Matsuse M, Lau C, Ryder M, Nishihara E, Ghossein RA, Ladanyi M, Yamashita S, Mitsutake N \& Fagin JA 2012 Absence of common activating mutations of the epidermal growth factor receptor gene in thyroid cancers from American and Japanese patients. International Journal of Cancer 130 2215-2217. (https://doi. org/10.1002/ijc.26267)

Rogounovitch TI, Bychkov A, Takahashi M, Mitsutake N, Nakashima M, Nikitski AV, Hayashi T, Hirokawa M, Ishigaki K, Shigematsu K, et al. 2015 The common genetic variant rs944289 on chromosome $14 \mathrm{q} 13.3$ associates with risk of both malignant and benign thyroid tumors in the Japanese population. Thyroid 25 333-340. (https://doi. org/10.1089/thy.2014.0431)

Schwarzenbach H, Hoon DS \& Pantel K 2011 Cell-free nucleic acids as biomarkers in cancer patients. Nature Review of Cancer 11 426-437. (https://doi.org/10.1038/nrc3066)

Shao Y, Ye M, Jiang X, Sun W, Ding X, Liu Z, Ye G, Zhang X, Xiao B \& Guo J 2014 Gastric juice long noncoding RNA used as a tumor marker for screening gastric cancer. Cancer 120 3320-3328. (https:// doi.org/10.1002/cncr.28882)

Siegel RL, Miller KD \& Jemal A 2017 Cancer statistics, 2017. CA: Cancer Journal for Clinicians 67 7-30. (https://doi.org/10.3322/caac.21387)

Sinicropi D, Qu K, Collin F, Crager M, Liu ML, Pelham RJ, Pho M, Dei Rossi A, Jeong J, Scott A, et al. 2012 Whole transcriptomeRNA-Seq analysis of breast cancer recurrence risk using formalin-fixed 
paraffin-embedded tumor tissue. PLoS ONE 7 e40092. (https://doi. org/10.1371/journal.pone.0040092)

Sun W, Lan X, Wang Z, Dong W, He L, Zhang T \& Zhang H 2016 Overexpression of long non-coding RNA NR_036575.1 contributes to the proliferation and migration of papillary thyroid cancer. Medical Oncology 33 102. (https://doi.org/10.1007/s12032-016-0816-y)

Taft RJ, Pheasant M \& Mattick JS 2007 The relationship between nonprotein-coding DNA and eukaryotic complexity. Bioessays $\mathbf{2 9}$ 288-299. (https://doi.org/10.1002/bies.20544)

Takahashi M, Saenko VA, Rogounovitch TI, Kawaguchi T, Drozd VM, Takigawa-Imamura H, Akulevich NM, Ratanajaraya C, Mitsutake N, Takamura N, et al. 2010 The FOXE1 locus is a major genetic determinant for radiation-related thyroid carcinoma in Chernobyl. Human Molecular Genetics 19 2516-2523. (https://doi.org/10.1093/ hmg/ddq123)

Takahashi Y, Sawada G, Kurashige J, Uchi R, Matsumura T, Ueo H, Takano Y, Eguchi H, Sudo T, Sugimachi K, et al. 2014 Amplification of PVT-1 is involved in poor prognosis via apoptosis inhibition in colorectal cancers. British Journal of Cancer 110 164-171. (https://doi. org/10.1038/bjc.2013.698)

Tang H, Wu Z, Zhang J \& Su B 2013 Salivary lncRNA as a potential marker for oral squamous cell carcinoma diagnosis. Molecular Medicine Reports 7 761-766. (https://doi.org/10.3892/mmr.2012.1254)

Trapnell C, Williams BA, Pertea G, Mortazavi A, Kwan G \& van Baren MJ 2010 Transcript assembly and quantification by RNA-Seq reveals unannotated trans-cripts and isoform switching during cell differentiation. Nature Biotechnology 28 511-515. (https://doi. org/10.1038/nbt.1621)

Tripathi V, Ellis JD, Shen Z, Song DY, Pan Q, Watt AT, Freier SM, Bennett CF, Sharma A, Bubulya PA, et al. 2010 The nuclear-retained noncoding RNA MALAT1 regulates alternative splicing by modulating SRsplicing factor phosphorylation. Molecular Cell 39 925-938. (https://doi.org/10.1016/j.molcel.2010.08.011)

Tye CE, Gordon JA, Martin-Buley LA, Stein JL, Lian JB \& Stein GS 2015 Could IncRNAs be the missing links in control of mesenchymal stem cell differentiation? Journal of Cellular Physiology 230 526-534. (https://doi.org/10.1002/jcp.24834)

Vogelstein B \& Kinzler KW 2004 Cancer genes and the pathways they control. Nature Medicine 10 789-799. (https://doi.org/10.1038/ nm1087)

Wang XS, Zhang Z, Wang HC, Cai JL, Xu QW, Li MQ, Chen YC, Qian XP, Lu TJ, Yu LZ, et al. 2006 Rapid identification of UCA1 as a very sensitive and specific unique marker for human bladder carcinoma. Clinical Cancer Research 12 4851-4858. (https://doi. org/10.1158/1078-0432.CCR-06-0134)

Wang J, Lu F, Ren Q, Sun H, Xu Z, Lan R, Liu Y, Ward D, Quan J, Ye T, et al. 2011 Novel histone demethylase LSD1inhibitors selectively target cancer cells with pluripotent stem cell properties. Cancer Research $\mathbf{7 1}$ 7238-7249. (https://doi.org/10.1158/0008-5472.CAN-11-0896)

Wang Y, Guo Q, Zhao Y, Chen J, Wang S, Hu J \& Sun Y 2014a BRAFactivated long non-coding RNA contributes to cell proliferation and activates autophagy in papillary thyroid carcinoma. Oncology Letters 8 1947-1952.

Wang F, Yuan JH, Wang SB, Yang F, Yuan SX, Ye C, Yang N, Zhou WP, Li WL, Li W, et al. 2014b Oncofetal long noncoding RNA PVT1 promotes proliferation and stem cell-like property of hepatocellular carcinoma cells by stabilizing NOP2. Hepatology 60 1278-1290. (https://doi.org/10.1002/hep.27239)

Wang C, Yan G, Zhang Y, Jia X \& Bu P 2015 Long non-coding RNA MEG3 suppresses migration and invasion of thyroid carcinoma by targeting of Rac1. Neoplasma 62 541-549. (https://doi.org/10.4149/ neo_2015_065)

Wang Q, Yang H, Wu L, Yao J, Meng X, Jiang H, Xiao C \& Wu F 2016 Identification of specific long non-coding RNA expression: profile and analysis of association with clinicopathologic characteristics and
BRAF mutation in papillary thyroid cancer. Thyroid 26 1719-1732. (https://doi.org/10.1089/thy.2016.0024)

Wang Y, He H, Li W, Phay J, Shen R, Yu L, Hancioglu B \& de la Chapelle A 2017 MYH9 binds to lncRNA gene PTCSC2 and regulates FOXE1 in the 9q22 thyroid cancer risk locus. PNAS 114 474-479. (https://doi.org/10.1073/pnas.1619917114)

Watrin M, Dausse E, Lebars I, Rayner B, Bugaut A \& Toulmé JJ 2009 Aptamers targeting RNA molecules. Methods in Molecular Biology 535 79-105.

Xia S, Wang C, Ni X, Ni Z, Dong Y \& Zhan W 2017 NONHSAT076754 aids ultrasonography in predicting lymph node metastasis and promotes migration and invasion of papillary thyroid cancer cells. Oncotarget 8 2293-2306.

Xiang C, Zhang ML, Zhao QZ, Xie QP, Yan HC, Yu X, Wang P \& Wang Y 2017 LncRNA-SLC6A9-5:2: a potent sensitizer in 131I-resistant papillary thyroid carcinoma with PARP-1 induction. Oncotarget 8 22954-22967.

Xie H, Ma H \& Zhou D 2013 Plasma HULC as a promising novel biomarker for the detection of hepatocellular carcinoma. Biomedical Research International 2013136106.

Xing M 2005 BRAF mutation in thyroid cancer. Endocrine-Related Cancer 12 245-262. (https://doi.org/10.1677/erc.1.0978)

Xing M 2010 Genetic alterations in the phosphatidylinositol-3 kinase/ AktPathway in thyroid cancer. Thyroid 20 697-706. (https://doi. org/10.1089/thy.2010.1646)

Xing M 2013 Molecular pathogenesis and mechanisms of thyroid cancer. Nature Review of Cancer 13 184-199. (https://doi.org/10.1038/ $\operatorname{nrc3431)}$

Xing M, Liu R, Liu X, Murugan AK, Zhu G, Zeiger MA, Pai S \& Bishop J 2014 BRAF V600E and TERT promoter mutations cooperatively identify the most aggressive papillary thyroid cancer with highest recurrence. Journal of Clinical Oncology 32 2718-2726. (https://doi. org/10.1200/JCO.2014.55.5094)

Xiong X, Zhu H \& Chen X 2017 Low expression of long noncoding RNA CASC2 indicates a poor prognosis and promotes tumorigenesis in thyroid carcinoma. Biomedicine and Pharmacotherapy 93 391-397.

Xu B, Shao Q, Xie K, Zhang Y, Dong T, Xia Y \& Tang W 2016 The long non-coding RNA ENST00000537266 and ENST00000426615 influence papillary thyroid cancer cell proliferation and motility. Cell Physiology and Biochemistry 38 368-378.

Yang M, Tian J, Guo X, Yang Y, Guan R, Qiu M, Li Y, Sun X, Zhen Y, Zhang $\mathrm{Y}$, et al. 2016 Long noncoding RNA are aberrantly expressed in human papillary thyroid carcinoma. Oncology Letters 12 544-552.

Yoon H, He H, Nagy R, Davuluri R, Suster S, Schoenberg D, Pellegata N $\&$ de LA Chapelle A 2007 Identification of a novel noncoding RNA gene, NAMA, that is downregulated in papillary thyroid carcinoma with BRAF mutation and associated with growth arrest. International Journal of Cancer 121 767-775. (https://doi.org/10.1002/ijc.22701)

Zhang R, Hardin H, Chen J, Guo Z \& Lloyd RV 2016 Non-coding RNAs in thyroid cancer. Endocrine Pathology 27 12-20. (https://doi. org/10.1007/s12022-016-9417-8)

Zhang R, Hardin H, Huang W, Chen J, Asioli S, Righi A, Maletta F, Sapino A \& Lloyd RV 2017a MALAT1 long non-coding rna expression in thyroid tissues: analysis by in situ hybridization and real-time PCR. Endocrine Pathology 28 7-12. (https://doi.org/10.1007/ s12022-016-9453-4)

Zhang D, Liu X, Wei B, Qiao G, Jiang T \& Chen Z 2017b Plasma lncRNA GAS8-AS1 as a potential biomarker of papillary thyroid carcinoma in Chinese patients. International Journal of Endocrinology 20172645904.

Zhang Y, Yu S, Jiang L, Wang X \& Song X 2017c HOTAIR is a promising novel biomarker in patients with thyroid cancer. Experimental and Therapeutic Medicine 13 2274-2278. (https://doi.org/10.3892/ etm.2017.4231)

Zhao J, Ohsumi TK, Kung JT, Ogawa Y, Grau DJ, Sarma K, Song JJ, Kingston RE, Borowsky M \& Lee JT 2010 Genome-wide identification http://erc.endocrinology-journals.org https://doi.org/10.1530/ERC-17-0188
C 2018 Society for Endocrinology Published by Bioscientifica Ltd. Printed in Great Britain 
of polycomb-associated RNAs by RIP-seq. Molecular Cell $\mathbf{4 0}$ 939-953. (https://doi.org/10.1016/j.molcel.2010.12.011)

Zhao JJ, Hao S, Wang LL, Hu CY, Zhang S, Guo LJ, Zhang G, Gao B, Jiang Y, Tian WG, et al. 2016 Long non-coding RNA ANRIL promotes the invasion and metastasis of thyroid cancer cells through TGF- $\beta$ / Smad signaling pathway. Oncotarget 7 57903-57918. (https://doi. org/10.18632/oncotarget.11087)

Zheng H, Wang M, Jiang L, Chu H, Hu J, Ning J, Li B, Wang D \& Xu J 2016 BRAF-activated long noncoding RNA modulates papillary thyroid carcinoma cell proliferation through regulating thyroid stimulating hormone receptor. Cancer Research Treatment $\mathbf{4 8}$ 698-707. (https://doi.org/10.4143/crt.2015.118)

Zhou Q, Chen J, Feng J \& Wang J 2015 Long noncoding RNA PVT1 modulates thyroid cancer cell proliferation by recruiting EZH2 and regulating thyroid-stimulating hormone receptor (TSHR). Tumour Biology 37 3105-3113. (https://doi.org/10.1007/s13277-015-4149-9) Zhu H, Lv Z, An C, Shi M, Pan W, Zhou L, Yang W \& Yang M 2016 Onco lncRNA HOTAIR and its functional genetic variants in papillary thyroid carcinoma. Scientific Reports 6 31969. (https://doi. org/10.1038/srep31969)

Received in final form 27 October 2017

Accepted 16 November 2017

Accepted preprint published online 16 November 2017
C) 2018 Society for Endocrinology Published by Bioscientifica Ltd. Printed in Great Britain 